University of Wollongong

Research Online

Australian Institute for Innovative Materials -

Papers

Australian Institute for Innovative Materials

$1-1-2015$

\title{
Split-half-tubular polypyrrole@sulfur@polypyrrole composite with a novel three-layer-3D structure as cathode for lithium/sulfur batteries
}

Xin Liang

University of Wollongong, x1475@uowmail.edu.au

Mingang Zhang

Taiyuan University of Science and Technology

Mohammad Kaiser

University of Wollongong, mrk912@uowmail.edu.au

Xuanwen Gao

University of Wollongong, xg973@uowmail.edu.au

Konstantin Konstantinov

University of Wollongong, konstan@uow.edu.au

See next page for additional authors

Follow this and additional works at: https://ro.uow.edu.au/aiimpapers

Part of the Engineering Commons, and the Physical Sciences and Mathematics Commons

Research Online is the open access institutional repository for the University of Wollongong. For further information contact the UOW Library: research-pubs@uow.edu.au 


\title{
Split-half-tubular polypyrrole@sulfur@polypyrrole composite with a novel three- layer-3D structure as cathode for lithium/sulfur batteries
}

\begin{abstract}
Polypyrrole@Sulfur@Polypyrrole composite with a novel three-layer-3D-structure,which consists of an external polypyrrole coating layer, an intermediate sulfur filling layer, and an internal polypyrrole split-halftube conducting matrix layer, has been synthesized by the oxidative chemical polymerization method and chemical precipitation method in this article. Due to this unique three-layer-structure, the discharge specific capacity of Polypyrrole@Sulfur@Polypyrrole composite cathode retained at 554mAh g- 1 after 50 cycles, which represents $68.8 \%$ retention of the initial discharge specific capacity. In comparison, the Sulfur@Polypyrrole composite cathode, with the same components as Polypyrrole@Sulfur@Polypyrrole composite, but without the three-layer-structure, has the discharge specific capacity of $370 \mathrm{mAh}$ g-1 after 50 cycles, which is $32.3 \%$ retention of the initial discharge specific capacity. Therefore, it can be concluded that the unique three-layer-structure plays an essential role in improving the performance of the Lithium/Sulfur batteries. Moreover, the effects of LiNO3 additive in the electrolyte on coulombic efficiency are discussed to further confirm the containment function of the external layer of polypyrrole in the Polypyrrole@Sulfur@Polypyrrole composite, which is the evidence that the external layer of polypyrrole can effectively confine the dissolved polysulfides.
\end{abstract}

\section{Keywords}

split, cathode, structure, 3d, layer, three, novel, composite, sulfur, batteries, polypyrrole, lithium, tubular, half

\section{Disciplines}

Engineering | Physical Sciences and Mathematics

\section{Publication Details}

Liang, X., Zhang, M., Kaiser, M. Rejaul., Gao, X., Konstantinov, K., Tandiono, R., Wang, Z., Liu, H., Dou, S. \& Wang, J. (2015). Split-half-tubular polypyrrole@sulfur@polypyrrole composite with a novel three-layer-3D structure as cathode for lithium/sulfur batteries. Nano Energy, 11 587-599.

\section{Authors}

Xin Liang, Mingang Zhang, Mohammad Kaiser, Xuanwen Gao, Konstantin Konstantinov, Richard Tandiono, Zhaoxiang Wang, Hua-Kun Liu, S X. Dou, and Jiazhao Wang 


\title{
Split-half-tubular Polypyrrole@Sulfur@Polypyrrole Composite with a Novel Three-layer-3D Structure as Cathode for Lithium/Sulfur Batteries
}

\author{
Xin Liang ${ }^{a}$, Mingang Zhang ${ }^{b}$,Mohammad Rejaul Kaiser ${ }^{a}$, Xuanwen Gao $^{a}$, Konstantin Konstantinov ${ }^{a}$, Richard \\ Tandiono $^{c}$, Zhaoxiang Wang ${ }^{d}$, Hua-Kun Liu ${ }^{a}$, Shi-Xue Dou ${ }^{a}$ and Jiazhao Wang*a \\ ${ }^{a}$ Institute for Superconducting and Electronic Materials, University of Wollongong, NSW 2519, Australia. \\ ${ }^{b}$ College of Materials Science and Engineering, Taiyuan University of Science and Technology, Taiyuan, Shanxi, 030024, \\ P.R.China \\ ${ }^{c}$ PT NIPRESS Tbk, J1.Raya Narogong KM. 26 Cileungsi, Bogor $16820 \quad$ Indonesia \\ ${ }^{d}$ Laboratory for Solid State Ionics, Institute of Physics, Chinese Academy of Sciences, PO Box 603, Beijing 100190, P. R. \\ China \\ *Corresponding author: Fax: +61 24221 5731;Tel: +61 24298 1478; E-mail:jiazhao@uow.edu.au (A/Prof. Jiazhao \\ Wang)
}

\section{Abstract}

Polypyrrole@Sulfur@Polypyrrole composite with a novel three-layer-3D-structure, which consists of an external polypyrrole coating layer, an intermediate sulfur filling layer, and an internal polypyrrole split-half-tube conducting matrix layer, has been synthesized by the oxidative chemical polymerization method and chemical precipitation method in this paper. Due to this unique three-layer-structure, the discharge specific capacity of Polypyrrole@Sulfur@Polypyrrole composite cathode retained at 554 $\mathrm{mAh} \mathrm{g}^{-1}$ after 50 cycles, which represents $68.8 \%$ retention of the initial discharge specific capacity. In comparison, the Sulfur@Polypyrrole composite cathode, with the same components as Polypyrrole@Sulfur@Polypyrrole composite, but without the three-layer-structure, has the discharge specific capacity of $370 \mathrm{mAh} \mathrm{g}^{-1}$ after 50 cycles, which is $32.3 \%$ retention of the initial discharge specific capacity. Therefore, it can be concluded that the unique three-layer-structure plays an essential role in improving the performance of the Lithium/Sulfur batteries. Moreover, the effects of $\mathrm{LiNO}_{3}$ additive in the electrolyte on coulombic efficiency are discussed to further confirm the containment 
function of the external layer of polypyrrole in the Polypyrrole@Sulfur@Polypyrrole composite, which is the evidence that the external layer of polypyrrole can effectively confine the dissolved polysulfides.

Keywords: Polypyrrole@Sulfur@Polypyrrole composite, three-layer-3D-structure, split-half-tubular, Lithium/Sulfur batteries

\section{Introduction}

Due to limited global energy supplies, environmental pollution, and the increasing consumption of energy, green and efficient energy storage devices are in high demand in modern society[1,2]. The lithium/sulfur battery is one of the most promising candidates, because the lithium/sulfur battery has the highest theoretical specific capacity of $1675 \mathrm{mAh} \mathrm{g}^{-1}$ among all the solid cathode lithium battery systems[3, 4]. It also has a very high specific energy density of $2500 \mathrm{Wh} \mathrm{kg}^{-1}$ or $2800 \mathrm{Wh} \mathrm{L}^{-1}[5-10]$. In addition, sulfur is abundant in nature, low-cost, and non-toxic[11].

Nevertheless, the fabrication of lithium/sulfur batteries has encountered a number of challenges. Sulfur is very much an electrically insulating material, which leads to poor electrochemical accessibility and low utilization in the electrode. The polysulfide anions, which are formed as the reaction intermediates, are highly soluble in the organic electrolyte solvent. The diffusion of polysulfides to the lithium anode results in low active material utilization, low coulombic efficiency, and short cycle life of the sulfur electrode[12, 13]. In order to operate the lithium-sulfur battery, conductive agents should be introduced into the sulfur (by synthesizing composites of sulfur/conductive agents). It has been reported that mesoporous carbon, multiwalled carbon nanotubes, carbon fibre, reduced graphene oxide, and carbon black have all been applied to improve the electrochemical performance of the sulfur cathode in lithium/sulfur batteries[5, 6, 8-10, 14-31]. Recently, in addition to the various types of carbon, conducting polymers have been investigated for 
lithium/sulfur batteries as well[4, 7, 32-37].

Compared with carbon, conducting polymer has many advantages for the lithium/sulfur battery system [38, 39]. First of all, the conducting polymer/sulfur composite synthesis process is more feasible, because the synthesis only requires an in-situ one pot route below $100^{\circ} \mathrm{C}$, while the carbonization process usually requires very high temperature (above $600^{\circ} \mathrm{C}$ ), which is higher than the melting point of sulfur $\left(115^{\circ} \mathrm{C}\right)$. This makes synthesis of the carbon/sulfur composite by the in-situ one pot route very difficult. Moreover, conducting polymers have functional groups and unique chain structures, which can further confine the sulfur and the dissolved polysulfides by inter- and/or intra-chain bonding[40]. In addition, conducting polymers are soft and self-healing[41], which provides a solution to problems related to volume expansion and material pulverization. Finally, some polymers are electrochemically active, so that they contribute some capacity to the lithium/sulfur batteries by themselves[7].

Polyaniline, polyacrylonitrile,polypyrrole(PPy), poly(3,4-ethylenedioxythiophene) poly(styrenesulfonate)and polythiophene have been successfully applied in lithium/sulfur batteries and are reported to significantly improve the performance of lithium/sulfur batteries[32, 37, 42-44]. Among these conducting polymers, PPy is a promising choice because the redox potential of PPy treated with lithium ( $2.5 \mathrm{~V}$ vs. $\left.\mathrm{Li} / \mathrm{Li}^{+}\right)$is in the range of the redox potential of sulfur cathode in the lithium cell[37]. Therefore PPy not only acts as an electrically conducting agent, but also contributes to the capacity of the $\mathrm{S}$ cathode in the lithium/sulfur batteries. There are two major research directions in the investigation of PPy/sulfur cathode. One involves coating PPy on the surface of sulfur, while the other involves loading sulfur on the PPy. Coating with PPy is an efficient method to prevent polysulfide dissolution and to improve the conductivity between the composite particles. Wang et al. [7] first reported incorporating conductive polypyrrole into sulfur cathode. Nanosize polypyrrole particles were uniformly coated onto the surface of the sulfur powder, which significantly improved the electrical conductivity, the capacity, and the cycling durability in a lithium cell compared with the 
bare sulfur electrode. The Manthiram group[35] reported coating polypyrrole nano layers on orthorhombic bipyramidal sulfur as a cathode material for lithium/sulfur batteries, which showed better electrochemical stability, cyclability, and rate capability than pristine sulfur. The role of PPy containment in preventing polysulfide dissolution was not fully discussed in these two papers, however. Furthermore, coating with PPy makes a limited contribution to improving the conductivity of the interior of the sulfur particles, which leads to the low utilization of the sulfur. In contrast, loading sulfur on a PPy conductive matrix is an efficient method to enhance the conductivity of the composite. Zhang et al. [33] loaded sulfur on branched PPy to make lithium/sulfur battery cathode, which showed improved electrochemical performance, although loading sulfur on the surface of the PPy raises the issue of the dissolution of polysulfides again. In order to obtain a thin and uniform coating layer of sulfur, the PPy conductive matrix should have high surface area. A special structure for the PPy matrix thus has to be prepared.

In order to combine the advantages of the two directions mentioned above, a Polypyrrole@Sulfur@Polypyrrole composite (PPy@S@PPy composite) with a novel three-layer-3D structure is proposed by not only loading sulfur on PPy but also coating PPy on sulfur. The composite is synthesized by the oxidative chemical polymerization method and chemical precipitation method, which has an external PPy coating layer, an intermediate sulfur filling layer and an internal PPy conducting matrix layer. In order to analyze the function of this novel three-layer-structure of the PPy@S@PPy composite, a Sulfur@Polypyrrole composite (S@PPy composite) with the same components as the prepared PPy@S@PPy composite but without three-layer-structure was synthesized for comparison. At first, the preparation process is introduced and then the XRD, Raman spectra and TGA are employed for the components confirmation for these two synthesized composites. The morphology of the composites is investigated by TEM and SEM, which confirms the unique split-half-tube structure. This unique split-half-tube structure has many advantages, such as having 
higher surface area, improving the amount of sulfur loading and leading to a thin and uniform coating layer of sulfur. Next, the conductivity, capacity, reversibility and rate capability of the composite cathodes are valued by the electrochemical testing, which confirms the improvements of electrochemical performance due to this novel structure. At last, the effects of $\mathrm{LiNO}_{3}$ additive in the electrolyte on coulombic efficiency are tested, which further identify the exist of the external layer of PPy in the PPy@S@PPy composite and confirm the containment function of the external layer of PPy for trapping the dissolved polysulfides.

\section{Experimental Section}

\subsection{Materials:}

Sodium thiosulphate $\left(\mathrm{Na}_{2} \mathrm{~S}_{2} \mathrm{O}_{3}\right)$, oxalic acid $\left(\mathrm{H}_{2} \mathrm{C}_{2} \mathrm{O}_{4}\right)$, pyrrole monomer, sodium p-toluenesulphonate(PTS Na), $\mathrm{FeCl}_{3}$, TX-100, cetyltrimethylammonium bromide (CTAB), ammonium persulfate, and sulfur(S) were all purchased from Sigma Aldrich (Australia). All the chemicals were used as received without any further purification.

\subsection{Preparation process:}

The preparation route for PPy@S@PPy composite is shown in Figure S1 in the Supporting Information, and the mechanisms for the synthesis of two different morphologies of PPy (split-half tubes and cauliflower-like particles) are included in the Supporting Information as well[45]. How to design the synthesis steps is also discussed in the Supporting Information, and a summary is shown in Tables S1-1 and S1-2.

\subsubsection{Preparation of polypyrrole split-half-tubes:}

Polypyrrole split-half-tubes were synthesized by the oxidative chemical polymerization method. $0.3 \mathrm{~g}$ liquid pyrrole monomers and $0.25 \mathrm{~g}$ sodium p-toluenesulfonate (PTS Na) as a dopant were dispersed in 
a $26 \mathrm{mM}$ cetyltrimethylammonium bromide (CTAB) aqueous surfactant solution. Then, an oxidizing agent, ammonium persulfate ( $1 \mathrm{~g})$ aqueous solution, was gradually added into the above mixture to initiate the polymerization. All solutions were precooled to $0-5{ }^{\circ} \mathrm{C}$, and the polymerization in the final mixture went on at $0-5{ }^{\circ} \mathrm{C}$ for $12 \mathrm{~h}$. After reaction, the precipitates were filtrated and washed with deionized water and ethanol, then dried in a vacuum oven at $60{ }^{\circ} \mathrm{C}$ for $12 \mathrm{~h}$. Finally, a black powder was obtained.

\subsubsection{Preparation of S@PPy composite as precursor (named S@PPy composite (precursor)):}

Firstly, $32.10 \mathrm{mg}$ of the obtained PPy split-half-tubes were added into $50 \mathrm{~mL}$ aqueous solution with $470 \mu \mathrm{L}$ TX-100. After ultrasonication for $3 \mathrm{~h}$, the obtained uniform suspension was transferred to a $1500 \mathrm{~mL}$ aqueous solution with $3 \mathrm{mmol} \mathrm{Na} \mathrm{S}_{2} \mathrm{O}_{3}$. Then, $500 \mathrm{~mL}$ thiosulphate solution with $9 \mathrm{mmol}$ $\mathrm{H}_{2} \mathrm{C}_{2} \mathrm{O}_{4}$ was slowly dropped into the suspension under stirring. Sulfur was precipitated on the PPy split-half-tube network to form the S@PPy precursor composite according to the following reaction: $\mathrm{Na}_{2} \mathrm{~S}_{2} \mathrm{O}_{3}+\mathrm{H}_{2} \mathrm{C}_{2} \mathrm{O}_{4} \rightarrow \mathrm{Na}_{2} \mathrm{C}_{2} \mathrm{O}_{4}+\mathrm{SO}_{2} \uparrow+\mathrm{S} \downarrow+\mathrm{H}_{2} \mathrm{O}$. After reaction, the precipitates were filtrated and washed with deionized water and ethanol, then dried in a vacuum oven at $45^{\circ} \mathrm{C}$ for $36 \mathrm{~h}$.

\subsubsection{Preparation of PPy@S@PPy composite:}

The polypyrrole layer was coated on the surface of the S@PPy composite by an optimized chemical polymerization method using pyrrole monomer, sodium p-toluenesulphonate (PTS Na) as the dopant, and $\mathrm{FeCl}_{3}$ as the oxidant.

Preparation of Solution One: $57.88 \mathrm{mg}$ sodium p-toluenesulfonate (PTS Na) was dispersed in $140 \mathrm{~mL}$ distilled water under stirring for 30 min with the temperature kept at $0-5^{\circ} \mathrm{C}$. Then $60 \mu \mathrm{L}$ liquid pyrrole monomer was added into the above solution under stirring for $30 \mathrm{~min}$ with the temperature kept at $0-5$ ${ }^{\circ} \mathrm{C}$ as well.

Preparation of Solution Two: $217.6 \mathrm{mg} \mathrm{FeCl} 3$ was dissolved in $30 \mathrm{~mL}$ distilled water under stirring for 
30 min with the temperature kept at $0-5^{\circ} \mathrm{C}$.

Firstly, $400 \mu \mathrm{L}$ TX-100 and 40 mg S@PPy precursor composite were dispersed in 35 mL Solution One with $15 \mu \mathrm{L}$ liquid pyrrole monomers and $14.47 \mathrm{mg}$ sodium p-toluenesulfonate (PTS Na) as dopant and kept under stirring for $1 \mathrm{~h}$, with the temperature kept at $0-5^{\circ} \mathrm{C}$. Then, $15 \mathrm{~mL}$ Solution Two with 108.8 mg $\mathrm{FeCl}_{3}$ as an oxidizing agent was gradually dropped into the above mixture to initiate the polymerization. The mixture was stirred for $6 \mathrm{~h}$ and then aged for another $12 \mathrm{~h}$. All the solutions were precooled to $0-5{ }^{\circ} \mathrm{C}$, and all the polymerization took place at $0-5{ }^{\circ} \mathrm{C}$. The resultant black aqueous solution was washed thoroughly with distilled water until free of $\mathrm{FeCl}_{3}$. Finally, the black mass was dried at $45^{\circ} \mathrm{C}$ overnight under vacuum to yield PPy@S@PPy powder.

\subsubsection{Preparation of S@PPy composite for comparison:}

As well as the S@PPy precursor composite, another batch of S@PPy composite was also prepared for comparison. This S@PPy composite has the same ratio of sulfur to PPy as in the PPy@S@PPy composite.

Firstly, $33.56 \mathrm{mg}$ of the obtained PPy split-half-tubes were added into $50 \mathrm{~mL}$ aqueous solution with $470 \mu \mathrm{L}$ TX-100. After ultrasonication for $3 \mathrm{~h}$, the obtained uniform suspension was transferred to a $1500 \mathrm{~mL}$ aqueous solution with $2 \mathrm{mmol} \mathrm{Na}_{2} \mathrm{~S}_{2} \mathrm{O}_{3}$. Then, $500 \mathrm{~mL}$ thiosulphate solution with $6 \mathrm{mmol}$ $\mathrm{H}_{2} \mathrm{C}_{2} \mathrm{O}_{4}$ was slowly dropped into the suspension under stirring. Sulfur was precipitated on the PPy split-half-tube network to form S@PPy composite. After the reaction, the precipitate was filtrated and washed with deionized water and ethanol, then dried in a vacuum oven at $45^{\circ} \mathrm{C}$ for $36 \mathrm{~h}$.

\subsection{Physical Characterization:}

The structures of the as-prepared sulfur, S@PPy composite, and PPy@S@PPy composite were characterized by X-ray diffraction (XRD) using a GBC MMA X-ray generator and diffractometer with

$\mathrm{Cu} \mathrm{K \alpha}$ radiation $(\lambda=1.5418 \AA)$, employing a scanning rate of $5^{\circ} \mathrm{min}^{-1}$ in the $2 \theta$ range from $10^{\circ}$ to 
$70^{\circ}$.Raman spectroscopy was conducted on a JOBIN YVON HR800 Confocal Raman system with $632.8 \mathrm{~nm}$ diode laser excitation on a 300 lines $/ \mathrm{mm}$ grating at room temperature. Thermogravimetric analysis (TGA) was performed via a SETARAM Thermogravimetric Analyzer (France) in air to determine the changes in sample weight with increasing temperature and to estimate the amount of sulfur in the sample. The morphology of the samples was obtained with a field-emission scanning electron microscope (FESEM; JEOL 7500, $5 \mathrm{kV}$ ). The specific surface area of the powders was examined by gas (ultra-high purity nitrogen) sorption analysis using the Brunauer-Emmett-Teller (BET) method (Quanta Chrome Nova 1000). Transmission electron microscope (TEM) images and EDS mapping results were also collected (JEOL 2011).

\subsection{Electrochemical measurements:}

The S@PPy composite cathode and PPy@S@PPy composite cathode slurries were made by mixing 70 wt. \% composite with $20 \mathrm{wt}$ \% carbon black and $10 \mathrm{wt}$ \% polyvinylidenefluoride (PVDF) binder in N-methyl-2-pyrrolidinone (NMP) solvent. The slurries were spread onto aluminum foil substrates. The coated electrodes were dried in a vacuum oven at $50{ }^{\circ} \mathrm{C}$ for $24 \mathrm{~h}$ and then pressed. Subsequently, the electrodes were cut into a $1 \times 1 \mathrm{~cm}^{2}$ size. A conventional organic solvent electrolyte consisting of 1 molL $^{-1}$ lithium bis(trifluoromethane) sulfonamide (LiTFSI) in poly (ethylene glycol) dimethyl ether 500 (PEGDME 500) was used with $0.1 \mathrm{~mol} \mathrm{~L}^{-1} \mathrm{LiNO}_{3}$ as an additive. To compare the effect of the electrolyte, another electrolyte was also prepared, which was $1 \mathrm{molL}^{-1} \mathrm{LiTFSI}$ in 1,3-dioxolane (DOL) / 1,2-dimethoxyethane (DME) (1:1 by volume) with $0.1 \mathrm{molL}^{-1} \mathrm{LiNO}_{3}$ as an additive.CR 2032 type coin cells were assembled in an Ar-filled glove box. Charge-discharge testing was carried out with a LAND battery test system at a current density of $50 \mathrm{~mA} \mathrm{~g}^{-1}$ within the voltage range of $1.5-3.0 \mathrm{~V}$. Cyclic voltammetry $(\mathrm{CV})$ and $\mathrm{AC}$ impedance measurements were performed using a Biologic VMP-3 Multichannel electrochemistry workstation at a scanning rate of $0.1 \mathrm{mV} \mathrm{s}^{-1}$ and over a frequency range of $100 \mathrm{kHz}-0.01 \mathrm{~Hz}$, respectively. 


\section{Results and Discussion}

Figure 1 presents the X-ray diffraction (XRD) patterns of the commercial sulfur, S@PPy composite, and PPy@S@PPy composite. The diffraction peaks of the three samples match very well with the standard diffraction lines of sulfur (PDF card No. 00-001-0478), which can be indexed to the orthorhombic phase with space group Fddd. This indicates that no phase transformation of sulfur occurs during the in-situ chemical polypyrrole coating process.

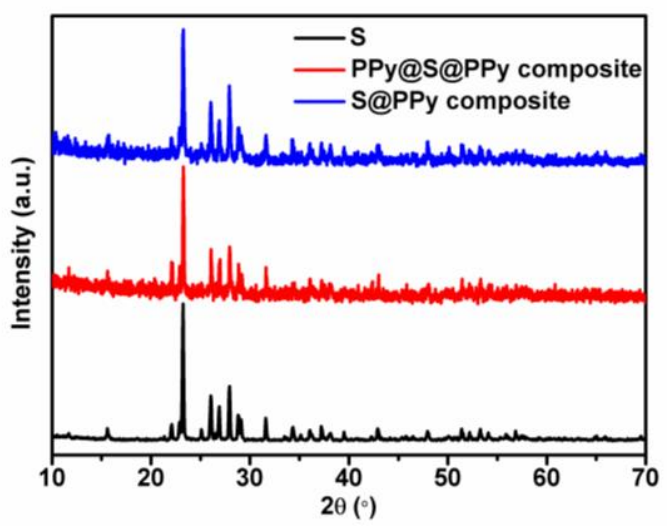

Figure 1.X-ray diffraction patterns of S, S@PPy composite, and PPy@S@PPy composite.

The Raman spectra of bare S, S@PPy composite, and PPy@S@PPy composite are shown in Figure2, which were obtained with $632.8 \mathrm{~nm}$ diode laser excitation at room temperature. The Raman spectrum of S displays three main peaks below $500 \mathrm{~cm}^{-1}$, while the peaks in the Raman spectrum of PPy are located between 800 and $1700 \mathrm{~cm}^{-1}$, which are identified as the characteristic peaks of $\mathrm{C}=\mathrm{C}$ backbone stretching of PPy at $1580 \mathrm{~cm}^{-1}, \mathrm{C}-\mathrm{H}$ in-plane deformation at $1050 \mathrm{~cm}^{-1}$ and $1080 \mathrm{~cm}^{-1}, \mathrm{C}-\mathrm{H}$ out-of-plane bending of oxidized PPy at $930 \mathrm{~cm}^{-1}, \mathrm{~N}-\mathrm{H}$ in-plane bending at $1240 \mathrm{~cm}^{-1}$, and the ring-stretching mode of PPy at $1320 \mathrm{~cm}^{-1}$ and $1380 \mathrm{~cm}^{-1}$, respectively[46]. The Raman spectra of S@PPy composite and PPy@S@PPy composite show not only the three characteristic peaks of sulfur below $500 \mathrm{~cm}^{-1}$, but also the typical peaks of PPy between 800 and $1700 \mathrm{~cm}^{-1}$. This confirms that the S@PPy composite and PPy@S@PPy composite contain both elemental sulfur and PPy. 


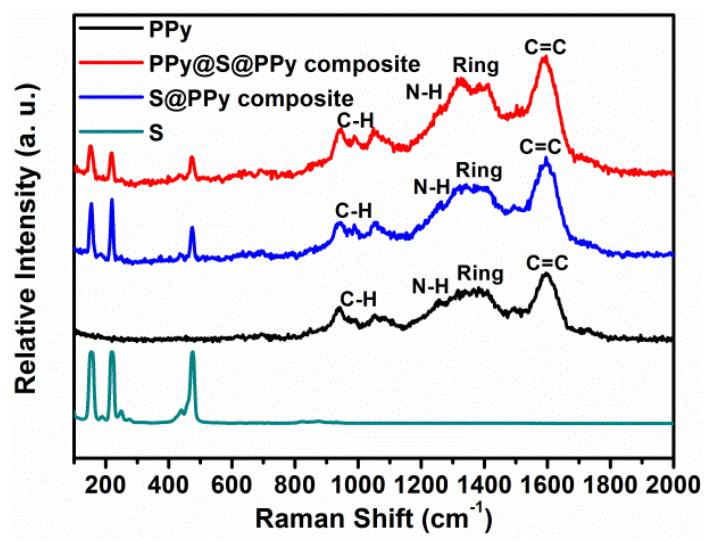

Figure 2.Raman spectra of S, PPy, S@PPy composite, and PPy@S@PPy composite.

To quantify the amount of the sulfur in the as-prepared S@PPy composite and the PPy@S@PPy composite, TGA analysis was carried out in air, with heating from $50^{\circ} \mathrm{C}$ to $800{ }^{\circ} \mathrm{C}$ at the rate of $5{ }^{\circ} \mathrm{C}$ $\min ^{-1}$. As shown in Figure 3, the commercial sulfur shows a weight loss starting at around $115^{\circ} \mathrm{C}$, which is the melting point of the elemental sulfur, and it was burned completely at around $230{ }^{\circ} \mathrm{C}$. PPy starts to be oxidised at around $220^{\circ} \mathrm{C}$. For the S@PPy composite and PPy@ S@PPy composite, sulfur is burned off at the first weight loss stage, followed by the decomposition of PPy at the second weight loss stage[35]. Thus, the S@PPy composite contains $64.7 \mathrm{wt} \%$ sulfur and 35.3wt\% polypyrrole, while the PPy@S@PPy composite is composed of 65.6 wt $\%$ sulfur and 34.4 wt\% polypyrrole. As shown in Fig. S2, the S@PPy precursor composite is composed of 73.6 wt $\%$ sulfur and 26.4 wt $\%$ polypyrrole, so it can be calculated that the PPy@S@PPy composite contains 10.9\% external PPy layer, 65.6\% sulfur, and 23.5\% inner PPy split-half-tubes. Therefore, the S@PPy composite and PPy@S@PPy composite have nearly the same components, but with different structures. Thus, it can be concluded that all the differences in the performance between the S@PPy composite and PPy@S@PPy composite are only related to the structure. 


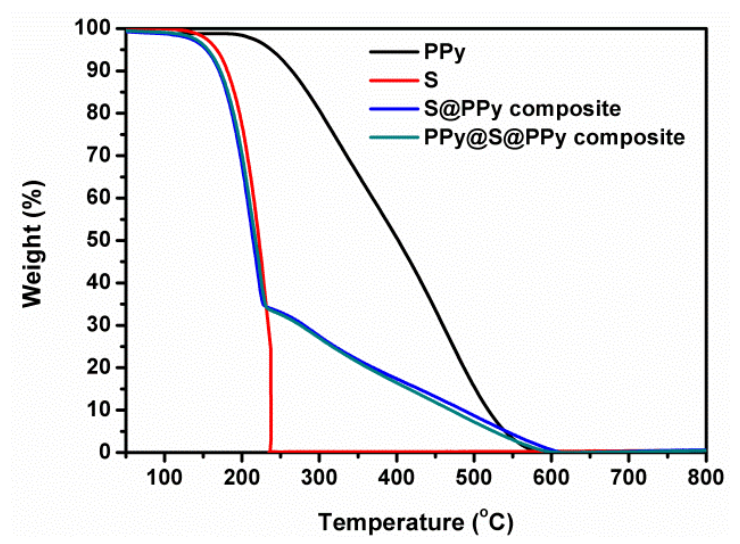

Figure 3.TGA curves of S, PPy, S@PPy composite, and PPy@S@PPy composite.

The morphology of the as-prepared PPy was investigated by transmission electron microscopy (TEM), as shown in Figure 4. In figure 4(a), the morphology of the as-prepared PPy features split-half-tubes, with diameters around 70-100 nm. It is interesting that the surfaces of these split-half-tubes are not smooth, which can also be seen in Fig. 4(b-d). It is clear that a great many PPy particles grow in a line to form the split-half-tubular structure, as shown in Fig. 4(d). This unique split-half-tube structure has many advantages in comparison with previous reports, such as having higher surface area, improving the amount of sulfur loading, and facilitating a thin and uniform coating layer of sulfur. The BET surface area of whole tubular PPy is $17.0 \mathrm{~m}^{2} \mathrm{~g}^{-1}$ in Ref.[47], and the sulfur loading is $30 \%$ and $50 \%$. In this work, on the other hand, the surface area of the split-half-tubular PPy is $57.4 \mathrm{~m}^{2} \mathrm{~g}^{-1}$, and the sulfur loading can be as high as $64.7 \%$ and $73.6 \%$. The contact between the surfaces of the split-half-tubular PPy and sulfur will be increased compared with the whole tubular structure, and therefore, the conductivity will be increased.

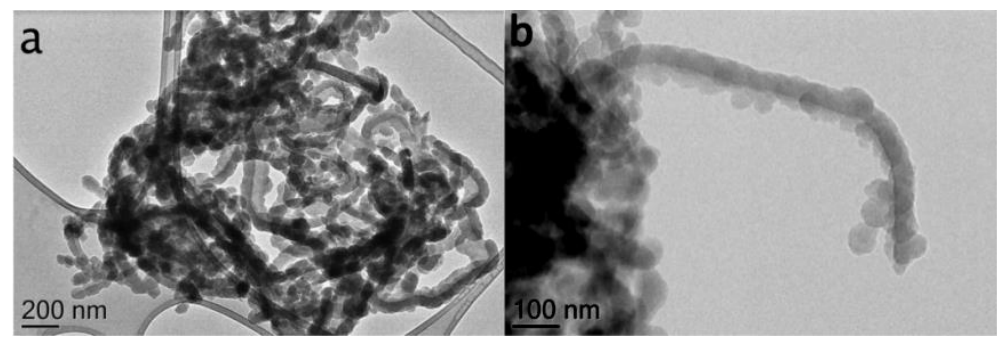




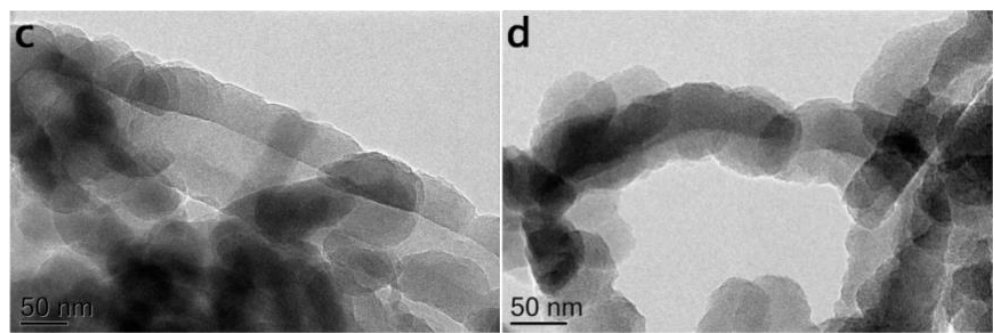

Figure 4. TEM images of PPy: (a) panoramic view at low magnification; (b) side view at high magnification; (c) front view at high magnification; (d) back view at high magnification.

The morphology of the as-prepared S@PPy composite and PPy@S@PPy composite was investigated by field-emission scanning electron microscopy (FESEM), as shown in Figure 5. The images of the as-prepared S@PPy composite and PPy@S@PPy composite reveal that the morphology of these two composites has kept the split-half-tube structure, with around 100-150 nm tube width, as shown in Figure 5(a, b). Figure S3 is a TEM image (secondary electron imaging mode) of the PPy@S@PPy composite. It is shown that the morphology of the external layer of PPy is typical cauliflower-like particles. TEM images of the PPy@S@PPy composite are also presented in Fig. S4. The images also reveal that the morphology of the PPy@S@PPy composite has kept the split-half-tube structure. The surface of the PPy@S@PPy composite has also become much smoother than that of the as-prepared PPy. The morphology of the S@PPy composite precursor for preparation of PPy@S@PPy composite is also presented in Fig. S5.

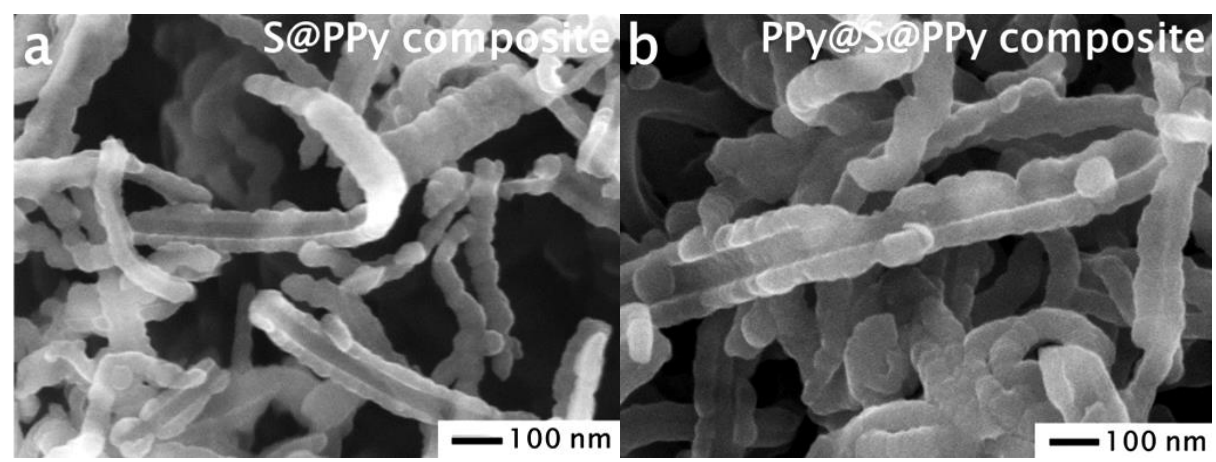

Figure 5.FESEM images of (a) S@PPy composite, (b) PPy@S@PPy composite. 
To verify that the sulfur was uniformly coated on the surfaces of the split-half tubes of PPy, energy dispersive X-ray spectroscopy (EDS) mapping analysis was carried out on the S@PPy composite (Fig. 6(a-d)). Figure 6(a) is a TEM image of the S@PPy composite. The red spots in Figure 6(b) correspond to the presence of the element carbon, and the green spots in Figure 6(c) correspond to the element nitrogen, in which $\mathrm{C}$ and $\mathrm{N}$ are the elements from polypyrrole. The yellow spots in Figure 6(d) correspond to the element sulfur. These results show that $\mathrm{S}$ is distributed uniformly throughout the whole area of the S@PPy composite, which indicates that the sulfur has uniformly coated the surfaces of the split-half tubes of PPy. EDS mapping analysis was also carried on the S@PPy composite (precursor) for confirming that the sulfur was uniformly coated on the surfaces of the split-half tubes of PPy, and the results are shown in Fig. S6. In order to show the sulfur distribution and the structure of the PPy@S@PPy composite, TEM and EDS mapping were conducted for the PPy@S@PPy composite, and the results are shown in Figure 6(e-h). Figure 6(e) is the TEM image of the PPy@S@PPy composite. The red spots in Figure 6(f) correspond to the presence of the element carbon, and the green spots in Figure 6(g) correspond to the element nitrogen, in which $\mathrm{C}$ and $\mathrm{N}$ are the elements from polypyrrole. From Figure 6(f) and (g), it is clear that the external PPy layer is very uniformly coated on the S@PPy split-half tubes. In Figure 6(h), the yellow spots correspond to the element sulfur. These results show that $\mathrm{S}$ is distributed uniformly throughout the whole area of the PPy@S@PPy composite. Thus, the uniform distribution of sulfur and the three-layer structure of the PPy@S@PPy composite have been confirmed. 


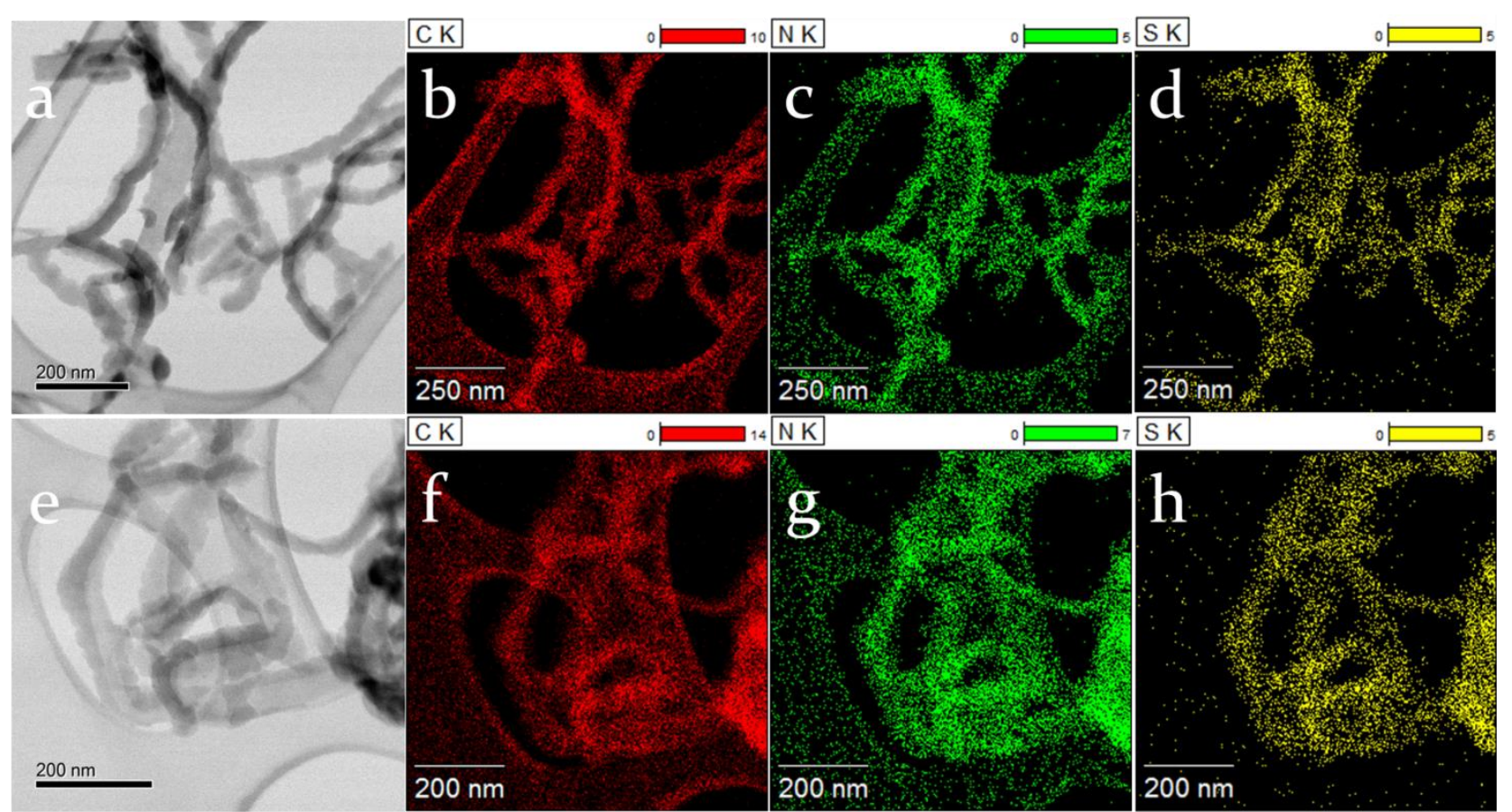

Figure 6. (1) S@PPy composite: (a) TEM image; (b) elemental mapping of Carbon; (c) elemental mapping of Nitrogen; (d) elemental mapping of Sulfur, (2) PPy@S@PPy composite: (e) TEM image; (f) elemental mapping of Carbon; (g) elemental mapping of Nitrogen; (h) elemental mapping of Sulfur.

To investigate the electrochemical characteristics of the S@PPy composite and PPy@S@PPy composite, cyclic voltammetry (CV) of the initial 5 cycles in 1 M LiTFSI in PEGDME 500 with $0.1 \mathrm{M}$ $\mathrm{LiNO}_{3}$ additive was conducted at a scan speed of $0.1 \mathrm{mV} \mathrm{s}^{-1}$ in the potential range of 1.5-3.0 V. In Figure 7, S@PPy composite and PPy@S@PPy composite exhibit similar electrochemical behaviour, in which two reduction peaks are observed, which could be assigned to the multiple-step reaction mechanism of sulfur with lithium. Specifically, in the first cycle, the peak at $2.4 \mathrm{~V}$ is ascribed to the open ring reduction of cyclic $\mathrm{S}_{8}$ to long chain lithium polysulfides $\left(\operatorname{Li}_{2} \mathrm{~S}_{\mathrm{x}}, 4 \leq \mathrm{x}<8\right)$, while the peak at $1.8 \mathrm{~V}$ corresponds to the further reduction of these high-order polysulfides to $\mathrm{Li}_{2} \mathrm{~S}_{2}$ and $\mathrm{Li}_{2} \mathrm{~S}$. The weak peak at $2.05 \mathrm{~V}$ is associated with the reduction of PPy [7]. It indicates that polypyrrole acts as not only a conducting additive, but also as an active material. From the first cycle onward, this peak becomes weaker and weaker in the CV profiles in Figure 7, which indicates that the lithium-storage capability of PPy has decreased. This phenomenon is in agreement with the cycling performance of PPy in 
Figure 9(b), which shows very large irreversible capacity at the initial cycle and obvious capacity decay during the cycling. From the second cycle to the fifth cycle, there are some differences between the S@PPy composite and the PPy@S@PPy composite. The reduction peaks of S@PPy composite are nearly at the same positions from the second cycle to the fifth cycle, while both of the reduction peaks of PPy@S@PPy composite are obviously shifted to higher voltage. This suggests that the electrochemical reactions during the first five cycles need to overcome the strong energy absorption of the conductive matrix and the outside layer of PPy[4].
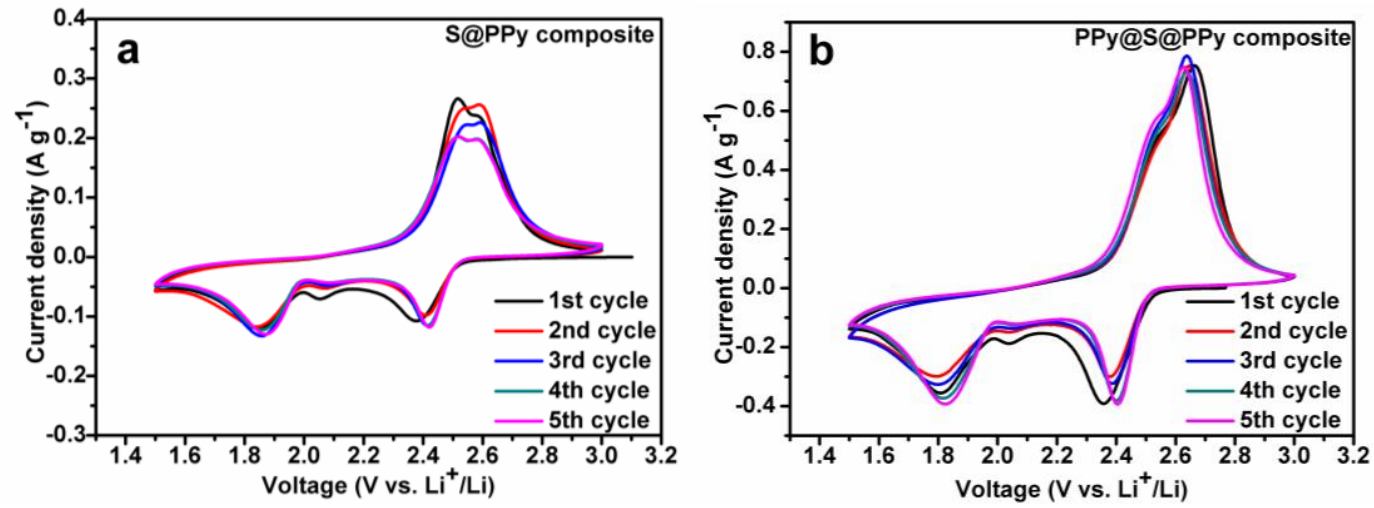

Figure 7.Cyclic voltammograms for the first 5 cycles of (a) S@PPy composite electrode; (b) PPy@ @ @PPy composite electrode.

Figure 8 shows representative charge and discharge voltage profiles of the $1^{\text {st }}, 2^{\text {nd }}, 5^{\text {th }}, 10^{\text {th }}$, and $20^{\text {th }}$ cycles of S@PPy composite and PPy@S@PPy composite electrodes in 1M LiTFSI in PEGDME 500 with $0.1 \mathrm{M} \mathrm{LiNO}_{3}$ additive at the current density of $50 \mathrm{~mA} \mathrm{~g}^{-1}$. The discharge curves present two plateaus for both cells, which are at 2.5 and $2.03 \mathrm{~V}$, respectively. They are assigned to the two-step reaction of sulfur with lithium during the discharge process. Comparing Figure 8(a) and (b), it is obvious that the PPy@S@PPy composite electrode shows much better reversibility than the S@PPy composite electrode. This confirms that the coating layer of PPy on the outside of the S@PPy composite can improve the cycling performance of the sulfur cathode. 

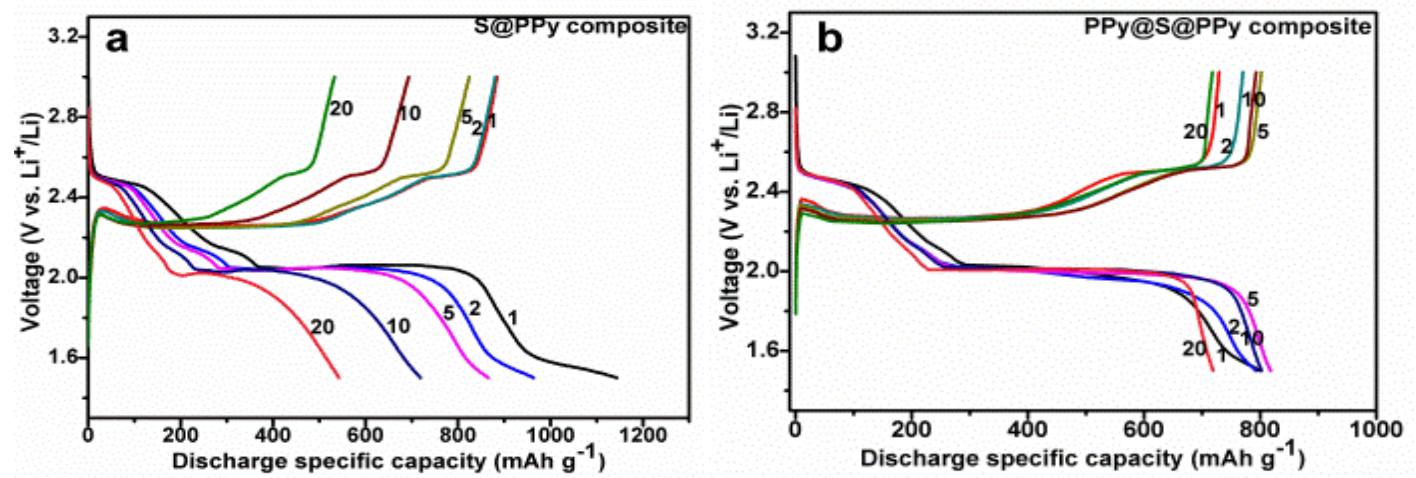

Figure 8. Discharge/charge curves for selected cycles of (a) S@PPy composite electrode; (b) PPy@S@PPy composite electrode.

Figure 9(a) presents the discharge specific capacities of S@PPy composite and PPy@S@PPy composite cathodes in 1M LiTFSI in PEGDME 500 with $0.1 \mathrm{M} \mathrm{LiNO}_{3}$ additive at the current density of 50mA g ${ }^{-1}$.It was found that the discharge specific capacity and the reversibility of the PPy@S@PPy composite electrode are much higher than for the S@PPy composite electrode. Specifically, PPy@S@PPy composite cathode shows better cycling performance, yielding a discharge specific capacity of $554 \mathrm{mAh} \mathrm{g}^{-1}$ after 50 cycles, which is approximately $68.8 \%$ retention of the initial discharge specific capacity of about $801 \mathrm{mAh} \mathrm{g}^{-1}$, while the S@PPy composite cathode presents the discharge specific capacity of $370 \mathrm{mAh} \mathrm{g}^{-1}$ after 50 cycles, representing about $32.3 \%$ retention of the initial discharge specific capacity of about $1145 \mathrm{mAh} \mathrm{g}^{-1}$. Thus, the capacity decay of PPy@S@PPy composite electrode is as low as $0.624 \%$ per cycle during these cycles, but the capacity decay of S@PPy composite electrode is as high as $1.354 \%$ per cycle. It should be noted that the PPy@S@PPy composite cathode delivers much lower discharge specific capacity in the first five cycles compared to S@PPy composite, which could be ascribed to the incomplete utilization of the active materials during the first few cycles of the PPy@S@PPy composite electrode. The sulfur in PPy@S@PPy composite electrode is covered by another PPy external layer, which means that the sulfur cannot be completely exposed to the electrolyte during the initial cycles, and the sulfur has to rearrange itself during the first few cycles, so that the inactive cores of sulfur are exposed to the electrolyte and then become able to 
be reutilized in subsequent cycles[15]. Fig. 9(b) shows that PPy can contribute some capacity to the lithium/sulfur battery, which can further confirm that PPy is an active material.
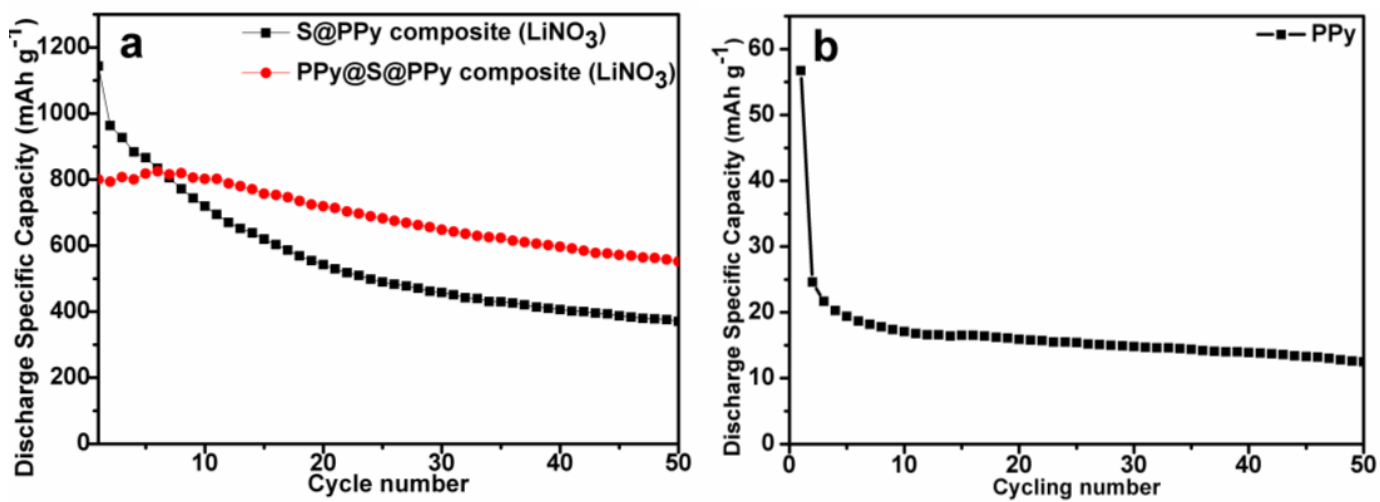

Figure 9. Discharge specific capacities of (a)S@PPy composite and PPy@S@PPy composite cathodes in PEGDME 500 electrolyte with $0.1 \mathrm{M} \mathrm{LiNO}_{3}$ additive; (b)polypyrrole electrode in PEGDME 500 electrolyte with $0.1 \mathrm{M} \mathrm{LiNO}_{3}$ additive.

In order to compare the rate capabilities of S@PPy composite and PPy@S@PPy composite cathodes, the cells were discharged to $1.5 \mathrm{~V}$ at different current densities from $50 \mathrm{~mA} \mathrm{~g}^{-1}$ to $1600 \mathrm{~mA}$ $\mathrm{g}^{-1}$ in PEGDME 500 electrolyte with $0.1 \mathrm{M} \mathrm{LiNO}_{3}$ additive, as shown in Figure 10(a). It should be noted that the PPy@S@PPy composite delivered a higher capacity when compared to the S@PPy composite, except for the first 5 cycles at the current density of $50 \mathrm{~mA} \mathrm{~g}^{-1}$, the reason for which has been explained in the discussion related to Figure 9. In addition, the PPy@S@PPy composite also presents much better reversibility compared to the S@PPy composite. When the current density was reduced to 50mA g ${ }^{-1}$, the PPy@S@PPy composite cathode recovered 87\% of its initial capacity, while S@PPy composite only recovered 42\%. These improvements in the PPy@S@PPy composite are achieved by the external coating layer of PPy, which can confine the dissolved polysulfides and decrease the loss of the active sulfur. Moreover, in PPy@S@PPy composite, the sulfur is confined in a limited space between the two layers of PPy, so that the charge transfer reactions could be enhanced because of good electronic contact between the sulfur and the PPy, leading to higher rate capacities in lithium sulfur batteries[27]. It is well known that, in comparison with PEGDME 500 solvent, 
1,3-dioxolane (DOL) and 1,2-dimethoxyethane (DME) have good ionic conductivity and low viscosity, which are essential to enhance the rate capabilities[22, 39]. Therefore, in order to optimize the high rate behaviour of the PPy@S@PPy composite cathode, 1 mol L $\mathrm{L}^{-1}$ lithium bis(trifluoromethane) sulfonamide (LiTFSI) in a mixed solvent of 1,3 -DOL/1,2-DME (1:1 by volume) with $0.1 \mathrm{~mol} \mathrm{~L}^{-1}$ $\mathrm{LiNO}_{3}$ as an additive was used as electrolyte to test the rate capabilities of the PPy@S@PPy composite cathode as well. As shown in Figure 9(b), when the current densities are lower than $200 \mathrm{~mA} \mathrm{~g}^{-1}$, there is no obvious difference between these two kinds of electrolyte. When the current density is higher than $200 \mathrm{~mA} \mathrm{~g}^{-1}$, however, the PPy@S@PPy composite cathode in the electrolyte with a mixed solvent of 1,3-dioxolane(DOL)/1,2-dimethoxyethane (DME) (1:1 by volume) presents much higher capacities than in the electrolyte with PEGDME solvent. In addition, when the current density is increased, the improvement becomes more obvious. The capacity is improved to $60 \mathrm{mAh} \mathrm{g}^{-1}$ at 400 $\mathrm{mA} \mathrm{g}^{-1}, 120 \mathrm{mAh} \mathrm{g}^{-1}$ at $800 \mathrm{~mA} \mathrm{~g}^{-1}$, and $160 \mathrm{mAh} \mathrm{g}^{-1}$ at $1600 \mathrm{~mA} \mathrm{~g}^{-1}$. This further confirms that the high-rate performance depends on the ion diffusion speed and the conductivity of the electrolyte solvent.
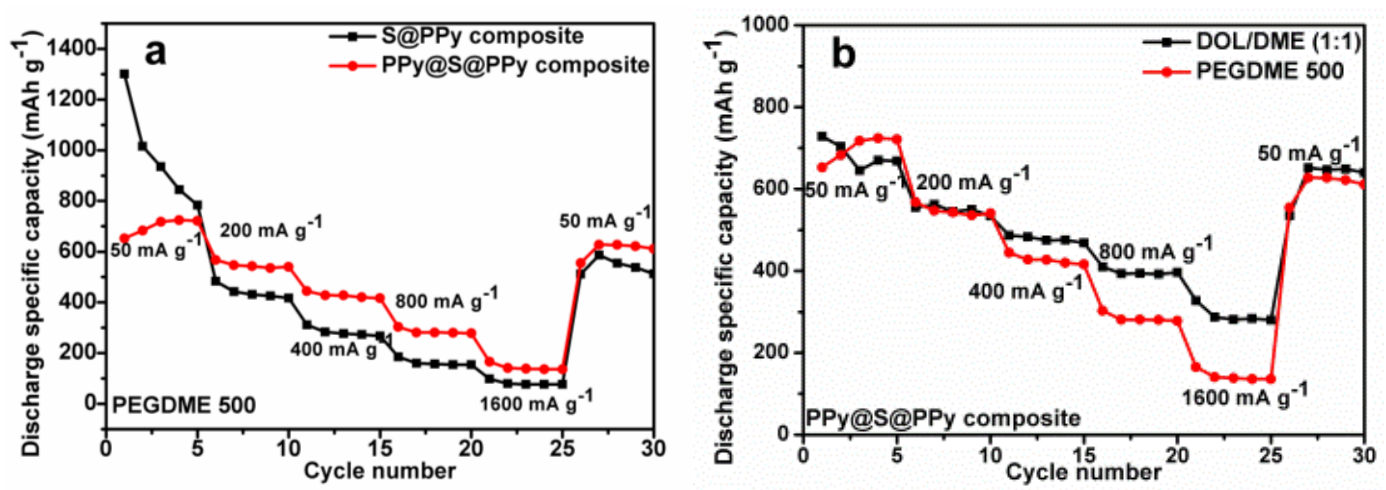

Figure 10. (a) Rate capabilities of S @PPy composite electrode and PPy@S@PPy composite electrode in PEGDME 500;

(b) rate capabilities of PPy@ S @PPy composite electrode in PEGDME 500 and DOL/DME (1/1).

Based on the above discussion, the improvement of the electrochemical performance of the cell with PPy@S@PPy composite cathode could be attributed to the multiple effects of the PPy additive and the superiority of the three-layer structure. 

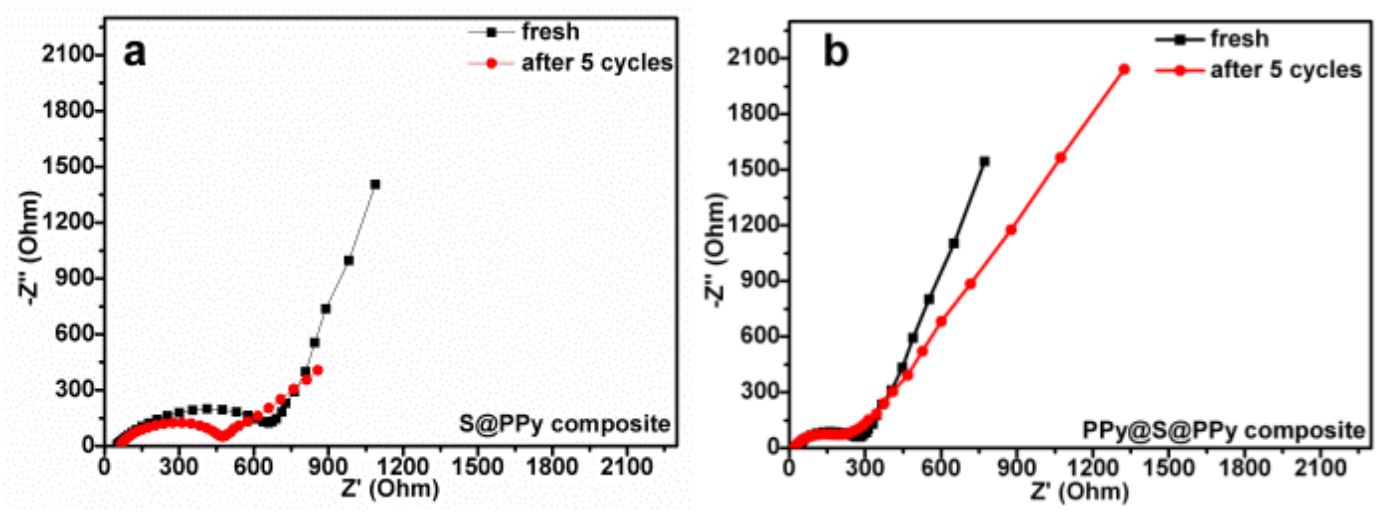

Figure 11. Impedance plots of (a) S@PPy composite electrode; (b) PPy@ S@PPy composite electrode.

(1) PPy is a kind of conducting polymer, so it works as a conducting additive. (2) As shown in Figure 9(b), PPy is also an active material contributing to the capacity of the electrode during cycling. This has been further confirmed by the CV measurements and the charge/discharge plateau data discussed above. (3) The internal PPy split-half-tube acts as a backbone to form the conducting network or the conducting matrix. Thereby, it can absorb the dissolved polysulfides and prevent the dissolution of polysulfides into the electrolyte to some degree, as well as improving the conductivity of the electrode at the same time. (4) The external PPy coating layer on the surface of the S@PPy composite can further improve the conductivity of the electrode. This can be confirmed by the electrochemical impedance spectroscopy (EIS) measurements in Figure 11. It is obvious that the impedance response exhibits a semicircular loop at high frequencies. The diameter of this semicircle gives the charge-transfer resistance, which corresponds to the charge transfer kinetics. The results show that the charge-transfer resistance of the cell with PPy@S@PPy composite electrode is lower than that of the cell made from S@PPy composite electrode, indicating that the conducting external PPy coating layer on the surface of the S@PPy composite has improved the electrochemical kinetics of the electrode in lithium/sulfur batteries. (5) In the PPy@S@PPy composite, the external PPy coating layer on the surface of the S@PPy composite also plays the role of container to trap the dissolved polysulfides, preventing them from dissolving in the electrolyte, and accommodates the volume expansion to reduce the pulverization of sulfur. 

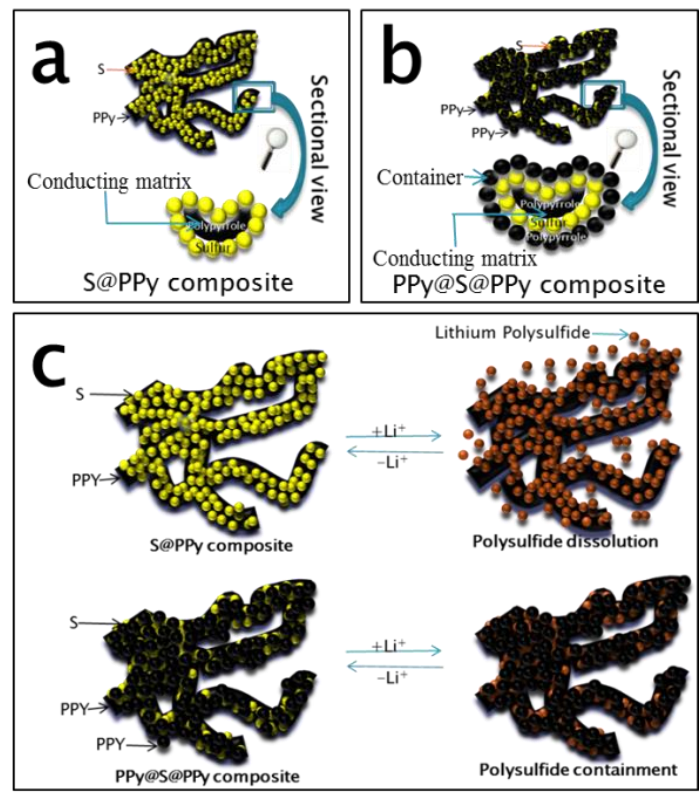

Figure 12. Proposed model and cross-sectional view of (a)S@PPy composite and (b)PPy@S@PPy composite; (c) schematic diagram of the function of the external PPy layer of PPy@ S@PPy composite towards trapping the dissolved polysulfides.

The proposed model and a cross-sectional view of the S@PPy composite are presented in Figure 12(a), where it is clear that the sulfur particles are loaded on the surface of the PPy fibre without any protection on the outside. In contrast, in the PPy@S@PPy composite, there is another PPy layer coating the surface of the S@PPy composite, as shown in Figure 12(b). Figure 12(c) contains a schematic diagram of the function of the external PPy coating layer on the surface of the S@PPy composite in the PPy@S@PPy composite. Without the external PPy layer protection, the dissolved polysulfides will diffuse out of the conducting matrix during charge-discharge processes. In contrast, when the external coating layer of PPy is present, polysulfides can be confined and prevented from diffusion into the electrolyte during the charge/discharge progress, so as to minimize the loss of the active materials in the cathode and improve the capacity and the cycling performance. Moreover, the containment function of the external PPy layer in PPy@S@PPy composite can be further confirmed by the coulombic efficiency results on the S@PPy composite electrode and the PPy@S@PPy composite electrode in the electrolyte with and without $\mathrm{LiNO}_{3}$ additive, as shown in Figure 13. It is well known 
that the dissolution and diffusion of the polysulfides in the electrolyte can lead to a "shuttle effect", which results in low coulombic efficiency in the lithium/sulfur battery system. It is also reported that the addition of $\mathrm{LiNO}_{3}$ as an additive in the electrolyte can improve the coulombic efficiency significantly[5, 48, 49]. Thus, as shown in Figure 13(a), the coulombic efficiency of the S@PPy composite cathode is significantly enhanced after adding $\mathrm{LiNO}_{3}$ into the electrolyte. This is because without the external PPy layer protection, quite a large amount of dissolved polysulfides diffuse to the lithium anode, which leads to a serious "shuttle effect", resulting in decreased coulombic efficiency. On adding $\mathrm{LiNO}_{3}$ additive to the electrolyte, a denser and more protective passivation film is formed on the lithium surface to protect the lithium anode and reduce the loss of the active sulfur, leading to the increase in the coulombic efficiency. In contrast, Figure 13(b) shows that there is no obvious improvement of the coulombic efficiency of the PPy@S@PPy composite cathode after adding $\mathrm{LiNO}_{3}$ to the electrolyte. This is because in PPy@S@PPy composite, there is an external layer of PPy, so nearly all the dissolved polysulfides will be trapped. The "shuttle effect" can thus be ignored to some extent. There may be only a slight amount of dissolved polysulfides in the lithium anode, so the coulombic efficiency will not gradually decrease, even without $\mathrm{LiNO}_{3}$ additive in the electrolyte, and the effect of $\mathrm{LiNO}_{3}$ is negligible on the PPy@S@PPy composite cathode. This is the most powerful evidence that the external layer of PPy can confine the dissolved polysulfides effectively. This is also the first time, to the best of our knowledge, that coulombic efficiency has been used to prove the containment function of the conducting polymer. 

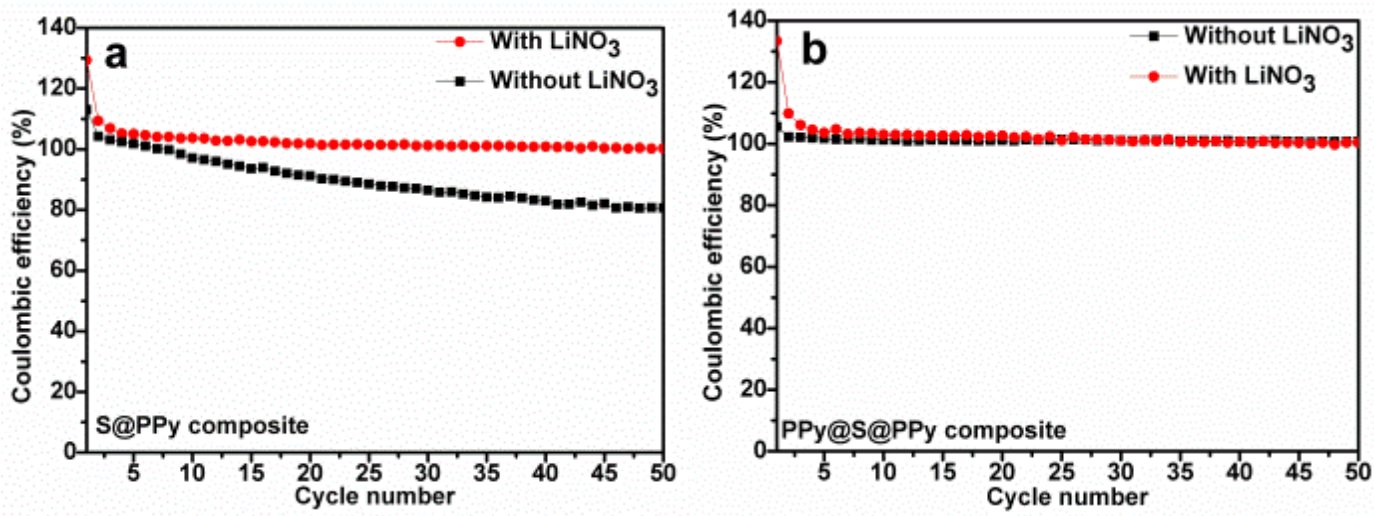

Figure 13. Coulombic efficiency of (a) S@PPy composite electrode, (b) PPy@S@PPy composite electrode with and without $\mathrm{LiNO}_{3}$ additive in the electrolyte.
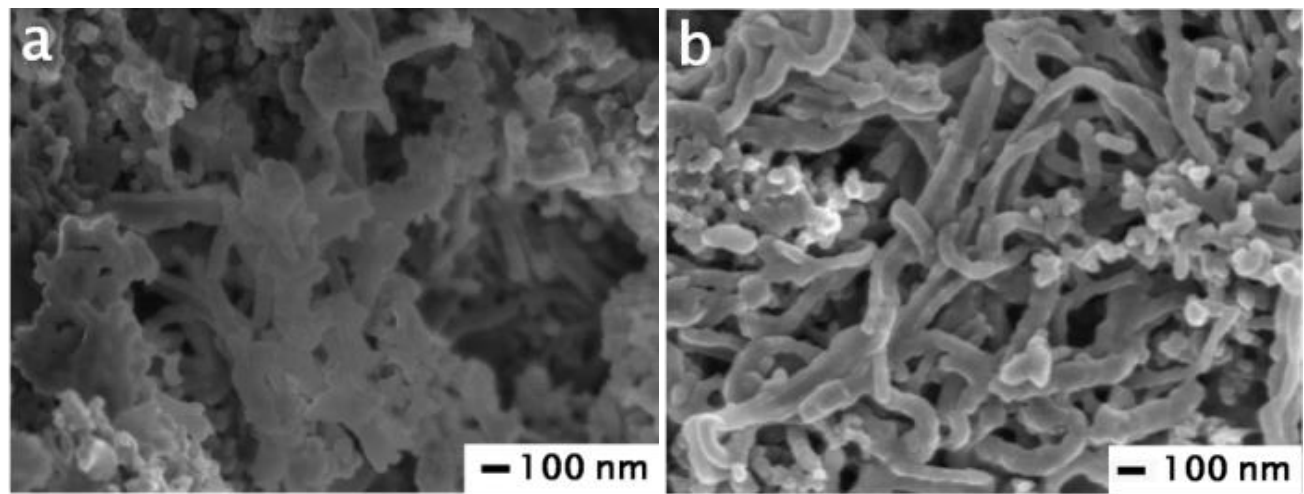

Figure 14. FESEM images of (a) S@PPy composite cathode after 100 cycles; (b) PPy@S@PPy composite cathode after 100 cycles.

When the cells were disassembled after 100 cycles, it was clear that the PPy@S@PPy composite offered better morphological control than the S@PPy composite during cycling, as shown in Fig. 14. Fig. 14(a) clearly shows the agglomeration of the S@PPy composite after the cycling. During the discharge and charge processes, without the protection of the external PPy layer, the dissolved polysulfides will diffuse in the electrolyte and leave the original position of the sulfur in the S@PPy composite, so that the sulfur will agglomerate. In contrast, no agglomeration of the PPy@S@PPy composite after cycling is observed in Fig. 14(b). In this case, the dissolved polysulfides are contained by the external PPy coating layer and will not diffuse. Due to the elastic properties of PPy, the volume expansion will be reduced as well. The better mechanical performance of the external PPy layer on the 
PPy@S@PPy composite and the role of the PPy external layer in confining the dissolved polysulfides are further confirmed.

\section{Conclusions}

A PPy@S@PPy composite with a novel three-layer-3D-structure, which consists of an external PPy coating layer, an intermediate sulfur filling layer, and an internal PPy conducting matrix layer, was synthesised by the oxidative chemical polymerization method and chemical precipitation method. The PPy@S@PPy composite has the same components with S@PPy composite except three-layer-3D-structure, which exhibits improved electrochemical performance. The discharge specific capacity of the PPy@S@PPy composite cathode is 554 mAh g ${ }^{-1}$ after 50 cycles, representing approximately $68.8 \%$ retention of the initial discharge specific capacity of about $801 \mathrm{mAh} \mathrm{g}^{-1}$, while

the S@PPy composite cathode demonstrates the discharge specific capacity of $370 \mathrm{mAh} \mathrm{g}^{-1}$ after 50 cycles, approximately $32.3 \%$ retention of the initial discharge specific capacity of about $1145 \mathrm{mAh} \mathrm{g}^{-1}$. It is also found that the PPy@S@PPy composite cathode in the electrolyte with a mixed solvent of 1,3-dioxolane (DOL)/1,2-dimethoxyethane (DME) (1:1 by volume) presents much higher capacity than in the electrolyte with PEGDME solvent when the current density is higher than $200 \mathrm{~mA} \mathrm{~g}^{-1}$. Moreover, the comparison experiments of $\mathrm{LiNO}_{3}$ additive in the electrolyte on coulombic efficiency confirm the containment function of the external PPy layer in the PPy@S@PPy composite and further identify the three layer structures of PPy@S@PPy composite.

\section{Acknowledgements}

Financial support provided by an Australian Research Council (ARC) Linkage Project (LP100100802) and industry partner PT Nipress TbK is gratefully acknowledged. We are also very grateful to DLG Battery Corp Ltd, Shanghai China for their support. Many thanks also go to Dr. Tania Silver for critical reading of the manuscript and valuable remarks. The first author also would like to thank the 
University of Wollongong as sponsor of the University Postgraduate Award and the International

Postgraduate Tuition Award.

\section{References}

[1] L. Wang, X. He, J. Li, J. Gao, J. Guo, C. Jiang, C. Wan, J. Mater. Chem., 22 (2012) 22077-22081.

[2] Y. Deng, Z. Li, Z. Shi, H. Xu, F. Peng, G. Chen, RSC Adv., 2 (2012) 4645-4647.

[3] X.B. Cheng, J.Q. Huang, Q. Zhang, H.J. Peng, M.Q. Zhao, F. Wei, Nano Energy, 4 (2014) 65-72.

[4] X. Liang, Z. Wen, Y. Liu, H. Zhang, J. Jin, M. Wu, X. Wu, J. Power Sources, 206 (2012) 409-413.

[5] L. Yin, J. Wang, X. Yu, C.W. Monroe, Y. NuLi, J. Yang, Chem. Commun., 48 (2012) 7868-7870.

[6] X.L. Ji, K.T. Lee, L.F. Nazar, Nat. Mater., 8 (2009) 500-506.

[7] J. Wang, J. Chen, K. Konstantinov, L. Zhao, S.H. Ng, G.X. Wang, Z.P. Guo, H.K. Liu, Electrochim. Acta, 51 (2006) 4634-4638.

[8] N.W. Li, M.B. Zheng, H.L. Lu, Z.B. Hu, C.F. Shen, X.F. Chang, G.B. Ji, J.M. Cao, Y. Shi, Chem. Commun., 48 (2012) 4106-4108.

[9] H. Wang, Y. Yang, Y. Liang, J.T. Robinson, Y. Li, A. Jackson, Y. Cui, H. Dai, Nano Lett., 11 (2011) 2644-2647.

[10] L. Ji, M. Rao, S. Aloni, L. Wang, E.J. Cairns, Y. Zhang, Energy Environ. Sci., 4 (2011) 5053-5059.

[11] M.S. Song, S.C. Han, H.S. Kim, J.H. Kim, K.T. Kim, Y.M. Kang, H.J. Ahn, S.X. Dou, J.Y. Lee, J. Electrochem. Soc., 151 (2004) A791-A795.

[12] B. Zhang, X. Qin, G.R. Li, X.P. Gao, Energy Environ. Sci., 3 (2010) 1531-1537.

[13] M. Nagao, A. Hayashi, M. Tatsumisago, Electrochim. Acta, 56 (2011) 6055-6059.

[14] G. Zhou, D.W. Wang, F. Li, P.X. Hou, L. Yin, C. Liu, G.Q. Lu, I.R. Gentle, H.-M. Cheng, Energy Environ. Sci., 5 (2012) 8901-8906.

[15] Y.S. Su, Y. Fu, A. Manthiram, Phys. Chem. Chem. Phys., 14 (2012) 14495-14499.

[16] M. Hagen, S. Doerfler, H. Althues, J. Tuebke, M.J. Hoffmann, S. Kaskel, K. Pinkwart, J. Power Sources, 213 (2012) 239-248.

[17] M. Rao, X. Song, E.J. Cairns, J. Power Sources, 205 (2012) 474-478.

[18] G. Zheng, Y. Yang, J.J. Cha, S.S. Hong, Y. Cui, Nano Lett., 11 (2011) 4462-4467.

[19] G. Zheng, Q. Zhang, J.J. Cha, Y. Yang, W. Li, Z.W. Seh, Y. Cui, Nano Lett., 13 (2013) 1265-1270.

[20] M. Rao, X. Song, H. Liao, E.J. Cairns, Electrochim. Acta, 65 (2012) 228-233.

[21] W. Ahn, K.B. Kim, K.N. Jung, K.H. Shin, C.S. Jin, J. Power Sources, 202 (2012) 394-399.

[22] G. He, X. Ji, L. Nazar, Energy Environ. Sci., 4 (2011) 2878-2883.

[23] Y.S. Su, A. Manthiram, Electrochim. Acta, 77 (2012) 272-278.

[24] C. Zhang, H.B. Wu, C. Yuan, Z. Guo, X.W. Lou, Angew. Chem., Int. Ed., 51 (2012) 9592-9595.

[25] J. Schuster, G. He, B. Mandlmeier, T. Yim, K.T. Lee, T. Bein, L.F. Nazar, Angew. Chem., Int. Ed., 51 (2012) $3591-3595$.

[26] C. Wang, W. Wan, J.T. Chen, H.H. Zhou, X.X. Zhang, L.X. Yuan, Y.H. Huang, J. Mater. Chem. A, 1 (2013) $1716-1723$.

[27] M.S. Park, J.S. Yu, K.J. Kim, G. Jeong, J.H. Kim, Y.N. Jo, U. Hwang, S. Kang, T. Woo, Y.J. Kim, Phys. Chem. Chem. Phys., 14 (2012) 6796-6804.

[28] S. Evers, L.F. Nazar, Chem. Commun., 48 (2012) 1233-1235.

[29] M.Q. Zhao, X.F. Liu, Q. Zhang, G.L. Tian, J.Q. Huang, W. Zhu, F. Wei, ACS Nano, 6 (2012) 10759-10769.

[30] J.Z. Wang, L. Lu, M. Choucair, J.A. Stride, X. Xu, H.K. Liu, J. Power Sources, 196 (2011) 7030-7034.

[31] Y.X. Wang, L. Huang, L.C. Sun, S.Y. Xie, G.L. Xu, S.R. Chen, Y.F. Xu, J.T. Li, S.L. Chou, S.X. Dou, S.G. Sun, J. Mater. Chem., 22 (2012) 4744-4750.

[32] Y. Yang, G.H. Yu, J.J. Cha, H. Wu, M. Vosgueritchian, Y. Yao, Z.A. Bao, Y. Cui, ACS Nano, 5 (2011) 9187-9193.

[33] Y. Zhang, Z. Bakenov, Y. Zhao, A. Konarov, T.N.L. Doan, M. Malik, T. Paron, P. Chen, J. Power Sources, 208 (2012) 1-8.

[34] Y. Fu, A. Manthiram, Chem. Mater., 24 (2012) 3081-3087.

[35] Y. Fu, A. Manthiram, J. Phys. Chem. C, 116 (2012) 8910-8915.

[36] L. Qiu, S. Zhang, L. Zhang, M. Sun, W. Wang, Electrochim. Acta, 55 (2010) 4632-4636.

[37] J. Wang, L. Lu, D. Shi, R. Tandiono, Z. Wang, K. Konstantinov, H. Liu, ChemPlusChem, 78 (2013) 318-324.

[38] S.S. Zhang, J. Power Sources, 231 (2013) 153-162.

[39] Y. Yang, G. Zheng, Y. Cui, Chem. Soc. Rev., 42 (2013) 3018-3032.

[40] L. Xiao, Y. Cao, J. Xiao, B. Schwenzer, M.H. Engelhard, L.V. Saraf, Z. Nie, G.J. Exarhos, J. Liu, Adv. Mater., 24 (2012) 
1176-1181.

[41] M.D. Hager, P. Greil, C. Leyens, S. van der Zwaag, U.S. Schubert, Adv. Mater., 22 (2010) 5424-5430.

[42] F. Wu, J. Chen, R. Chen, S. Wu, L. Li, S. Chen, T. Zhao, J. Phys. Chem. C, 115 (2011) 6057-6063.

[43] J. Wang, J. Yang, C. Wan, K. Du, J. Xie, N. Xu, Adv. Funct. Mater., 13 (2003) 487-492.

[44] S.C. Zhang, L. Zhang, W.K. Wang, W.J. Xue, Synthetic Metals, 160 (2010) 2041-2044.

[45] X. Zhang, J. Zhang, W. Song, Z. Liu, The Journal of Physical Chemistry B, 110 (2005) 1158-1165.

[46] I. Sultana, M.M. Rahman, S. Li, J. Wang, C. Wang, G.G. Wallace, H.K. Liu, Electrochim. Acta, 60 (2012) $201-205$.

[47] X. Liang, Y. Liu, Z. Wen, L. Huang, X. Wang, H. Zhang, J. Power Sources, 196 (2011) 6951-6955.

[48] Y.S. Su, A. Manthiram, Chem. Commun., 48 (2012) 8817-8819.

[49] S.S. Zhang, J.A. Read, J. Power Sources, 200 (2012) 77-82. 


\section{Split-half-tubular Polypyrrole@Sulfur@Polypyrrole Composite with a Novel Three-layer-3D Structure as Cathode for Lithium/Sulfur Batteries}

Xin Liang ${ }^{a}$, Mingang Zhang ${ }^{b}$,Mohammad Rejaul Kaiser ${ }^{a}$, Xuanwen Gao ${ }^{a}$, Konstantin Konstantinov ${ }^{a}$, Richard Tandiono $^{c}$, Zhaoxiang Wang ${ }^{d}$, Hua-Kun Liu ${ }^{a}$, Shi-Xue Dou ${ }^{a}$ and Jiazhao Wang ${ }^{* a}$

${ }^{a}$ Institute for Superconducting and Electronic Materials, University of Wollongong, NSW 2519, Australia. Fax: +61 2 4221 5731; Tel: +61 24298 1478; E-mail:jiazhao@uow.edu.au

${ }^{b}$ College of Materials Science and Engineering, Taiyuan University of Science and Technology, Taiyuan, Shanxi, 030024, P.R.China

${ }^{c}$ PT NIPRESS Tbk, J1.Raya Narogong KM. 26 Cileungsi, Bogor 16820 Indonesia

${ }^{d}$ Laboratory for Solid State Ionics, Institute of Physics, Chinese Academy of Sciences, PO Box 603, Beijing 100190, P. R. China 


\section{Electronic Supplementary Information (ESI)}

1. PPy split-half-tubes: (oxidative chemical polymerization method)

Pyrrole monomers, - 1 Ammonium

CTAB, PTS Na 7 persulfate

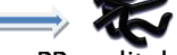

PPy split-half-tubes

2. S@PPy composite: (chemical precipitation method)

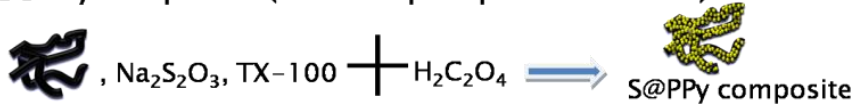

3.PPy@S@PPy composite: (oxidative chemical polymerization method)

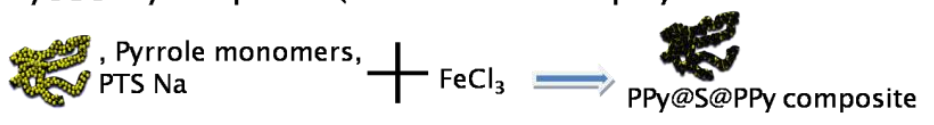

Figure S1. Preparation route for PPy@S@PPy composite.

Fig. S1 shows the preparation route for PPy@S@PPy composite. There are three steps: firstly, PPy split-half-tubes were prepared by the oxidative chemical polymerization method; sulfur was then loaded on the surface of the PPy split-half-tubes via the chemical precipitation method to synthesize the S@PPy composite; and finally, an external PPy layer was coated on the surface of the S@PPy composite by the oxidative chemical polymerization method to obtain the PPy@S@PPy composite. 


\section{The mechanism of synthesis of two different morphologies of PPy (split-half tubes and cauliflower-like particles):}

Both the surfactant and the oxidizing agent play key roles in controlling the morphology. During the synthesis of internal PPy, CTAB was used as the surfactant, and ammonium persulfate was added as oxidizing agent. CTAB is a kind of long-chain cationic surfactant, which prefers to form a lamellar mesostructure by self-assembly. A lamellar structure is formed between the cations of the CTAB and the anions of the oxidizing agent ammonium persulfate in the aqueous solution, which is credited with leading to the growth of the ribbon-like polypyrrole. The formation of the split-half-tubular polypyrrole nanostructure is considered to be a result of rolling up the ribbon-like polypyrrole. For the preparation of external PPy, on the other hand, TX-100 was used, which is a kind of non-ionic

surfactant. In this case, there is no soft template to form the lamellar structure. Thus, the typical cauliflower-like PPy was obtained." 


\section{Design synthesis steps:}

$\mathbf{1}^{\text {st }}$ step: To synthesize S@PPy composite (precursor) with the designed sulfur percentage of $74.9 \%$.

In this experiment, $3 \mathrm{mmol} \mathrm{Na} 2 \mathrm{~S}_{2} \mathrm{O}_{3}$ and $9 \mathrm{mmol} \mathrm{H}_{2} \mathrm{C}_{2} \mathrm{O}_{4}$ were used, and according to the reaction equation: $\mathrm{Na}_{2} \mathrm{~S}_{2} \mathrm{O}_{3}+\mathrm{H}_{2} \mathrm{C}_{2} \mathrm{O}_{4} \rightarrow \mathrm{Na}_{2} \mathrm{C}_{2} \mathrm{O}_{4}+\mathrm{SO}_{2} \uparrow+\mathrm{S} \downarrow+\mathrm{H}_{2} \mathrm{O}, 3$ mmol sulfur is expected to be obtained. As $32.1 \mathrm{mg}$ half-spilt tubes were added, the designed sulfur percentage should thus be: $(3 \times$ $32) /(3 \times 32+32.1) \times 100 \%=74.9 \%$. According to the TGA results, the real sulfur percentage is $73.6 \%$. Thus, the real sulfur percentage is very close to the designed sulfur percentage.

$2^{\text {nd }}$ step: To synthesize PPy@S@PPy composite with the designed sulfur percentage of 62.0\%.

In the S@PPy composite (precursor), the sulfur percentage is $73.6 \%$, and thus the split-half tubular percentage is $100 \%-73.6 \%=26.4 \% .40 \mathrm{mg} \mathrm{S} @ \mathrm{PPy}$ composite (precursor) was used for the preparation, in which the amount of sulfur is $40 \times 73.6 \%=29.44 \mathrm{mg}$, and the amount of split-half tubes is $40 \times$ $26.4 \%=10.56 \mathrm{mg}$. As it is usually possible to obtain $1 \mathrm{mg}$ PPy from $2 \mu \mathrm{L} \mathrm{Py}, 15 \mu \mathrm{L}$ Py was added in the experiment, and thus about $7.5 \mathrm{mg}$ PPy can be obtained. Then, the designed sulfur percentage in PPy@S@PPy composite is $29.44 /(40.0+7.5) \times 100 \%=62.0 \%$. The TGA results show that the real sulfur percentage in the PPy@S@PPy composite is 65.6\%. The real sulfur percentage is a little bit higher than the designed value, but it is still acceptable for design of synthesis a kind of material by chemical reaction method.

$\mathbf{3}^{\text {rd }}$ step: For comparison with PPy@S@PPy composite, to synthesize S@PPy composite with a designed sulfur percentage of $65.6 \%$.

In this experiment, $2 \mathrm{mmol} \mathrm{Na} 2 \mathrm{~S}_{2} \mathrm{O}_{3}$ and $6 \mathrm{mmol} \mathrm{H}_{2} \mathrm{C}_{2} \mathrm{O}_{4}$ were used, according to the reaction equation: $\mathrm{Na}_{2} \mathrm{~S}_{2} \mathrm{O}_{3}+\mathrm{H}_{2} \mathrm{C}_{2} \mathrm{O}_{4} \rightarrow \mathrm{Na}_{2} \mathrm{C}_{2} \mathrm{O}_{4}+\mathrm{SO}_{2} \uparrow+\mathrm{S} \downarrow+\mathrm{H}_{2} \mathrm{O}$, so 2 mmol sulfur is expected to be obtained. As $33.56 \mathrm{mg}$ half-spilt tubes were added, the designed sulfur percentage should be: $(2 \times 32) /(2 \times$ $32+33.56) \times 100 \%=65.6 \%$. According to the TGA results, the real sulfur percentage is $64.7 \%$. Thus the real sulfur percentage is very close to the designed sulfur percentage.

There are three main points to realizing the controllable synthesis of the composite:

1. General principles for synthesis of PPy using Py: $2 \mu \mathrm{L}$ Py $\rightarrow 1 \mathrm{mg}$ PPy

2. Amounts of PTSNa and $\mathrm{FeCl}_{3}$ (Mole Ratio): $\quad \mathrm{Py}: \mathrm{PTSNa}=3: 1, \mathrm{Py}: \mathrm{FeCl}_{3}=1: 3$

3. Accurately control the added amount of Py by preparing Solution One and Solution Two. Only $1 / 4$ Solution One and $1 / 2$ Solution Two are used for the synthesis. 
Table S1-1 Summary of the designed and calculated sulfur percentages of S@PPy composite and S@PPy composite (precursor). (precursor)

\begin{tabular}{lllll} 
& \multicolumn{2}{c}{ Split-half } & Sulfur & \multicolumn{2}{c}{ S percentage } \\
Name & PPy tubes & {$[$ Designed] } & Designed & TGA \\
& $33.56 \mathrm{mg}$ & $2 \mathrm{mmol} \times 32 \mathrm{~g} \mathrm{~mol}^{-1}$ & $65.6 \%$ & $64.7 \%$ \\
S@PPy composite & & & & \\
$\begin{array}{l}\text { S@PPy composite } \\
\text { (precursor) }\end{array}$ & $32.1 \mathrm{mg}$ & $3 \mathrm{mmol} \times 32 \mathrm{~g} \mathrm{~mol}^{-1}$ & $74.9 \%$ & $73.6 \%$
\end{tabular}

\section{S@PPy composite (precursor).}

Table S1-2 Summary of the calculated sulfur percentages of PPy@S@PPy composite.

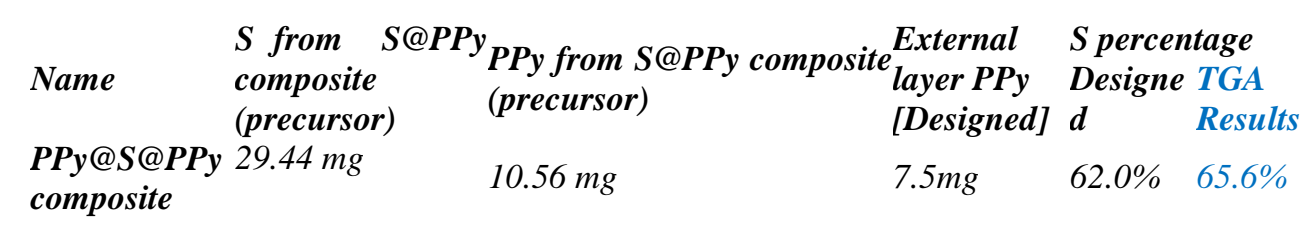

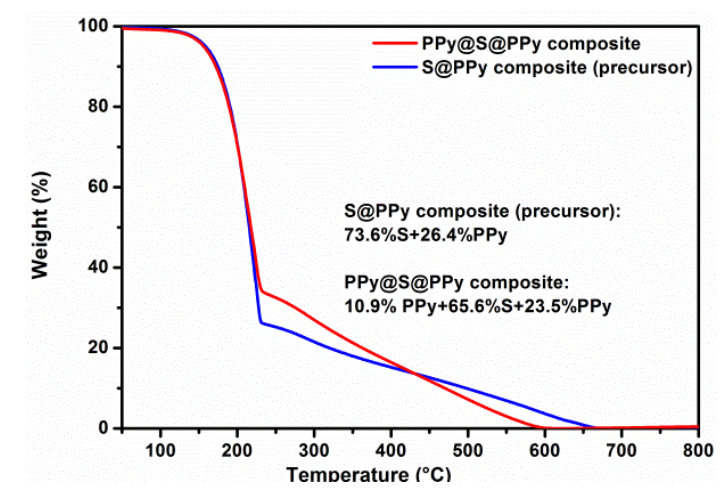

Figure S2. TGA curves of: S@PPy composite (precursor) and PPy@S@PPy composite.

Figure S2 presents the TGA curves of the S@PPy composite (precursor) and the as-prepared PPy@S@PPy composite. It is shown that the S@PPy composite (precursor) consists of 73.6\% sulfur and 26.4\% PPy, and the PPy@S@PPy composite is composed of 65.6 wt $\%$ sulfur and 34.4 wt $\%$ polypyrrole. According to Figure 6(e-h), sulfur and PPy are both uniformly distribute in the whole PPy@S@PPy composite, the formation of the external PPy layer is confirmed. So it can be calculated that the PPy@S@PPy composite contains 10.9\% external PPy layer, 65.6\% sulfur, and 23.5\% inner PPy split-half-tubes. 


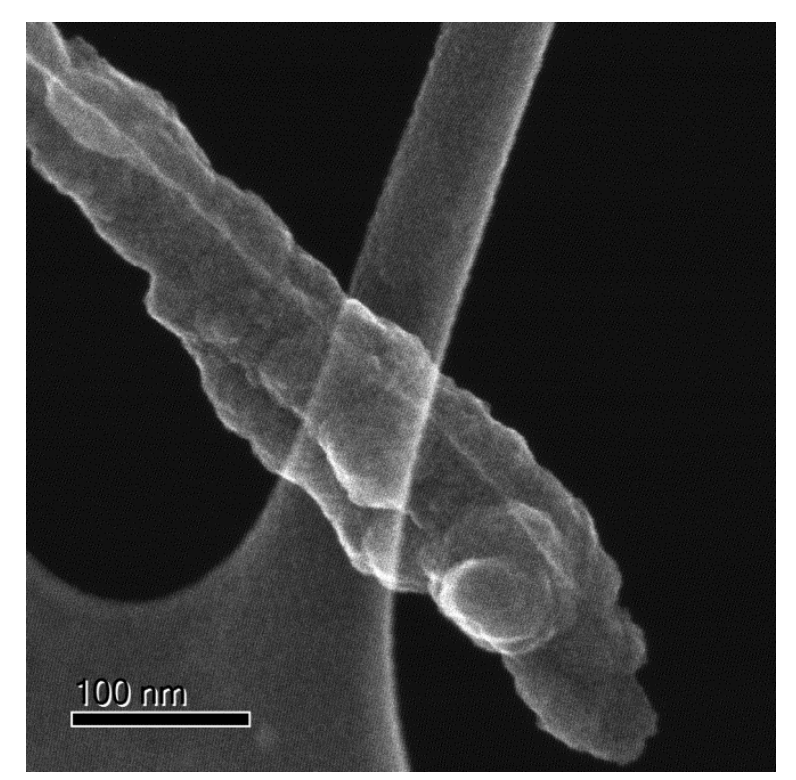

Figure S3 TEM image (secondary electron imaging mode) of the PPy@S@PPy composite Figure S3 is a TEM image (secondary electron imaging mode) of the PPy@S@PPy composite. It is shown that the morphology of the external layer of PPy is typical cauliflower-like particles. 


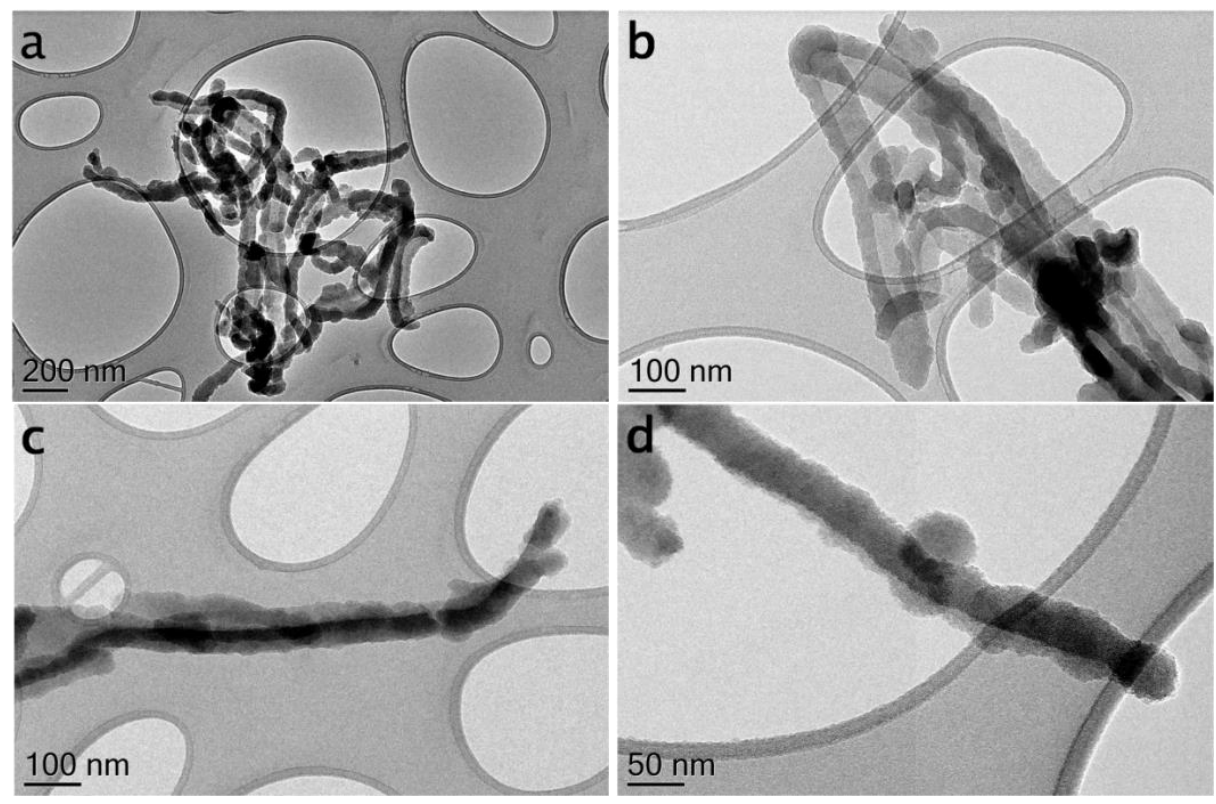

Figure S4. TEM images of PPy@S@PPy composite at different magnifications and from different viewpoints.

Fig S4 presents TEM images of the as-prepared PPy@S@PPy composite at different magnifications and from different viewpoints. The images reveal that the morphology of the PPy@S@PPy composite has kept the split-half-tube structure with around $100 \mathrm{~nm}-150 \mathrm{~nm}$ tube width. The surface has also become much smoother than in the as-prepared PPy split-half-tubes. 


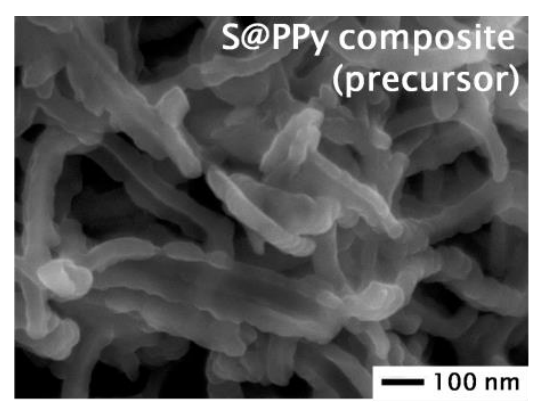

Figure S5. FESEM image of S@PPy composite as precursor for preparation of PPy@S@PPy composite.

Figure S5 contains a FESEM image of the S@PPy composite as precursor to prepare PPy@S@PPy composite. It is clearly shown that the morphology has kept the split-half-tube structure with rough surfaces. 

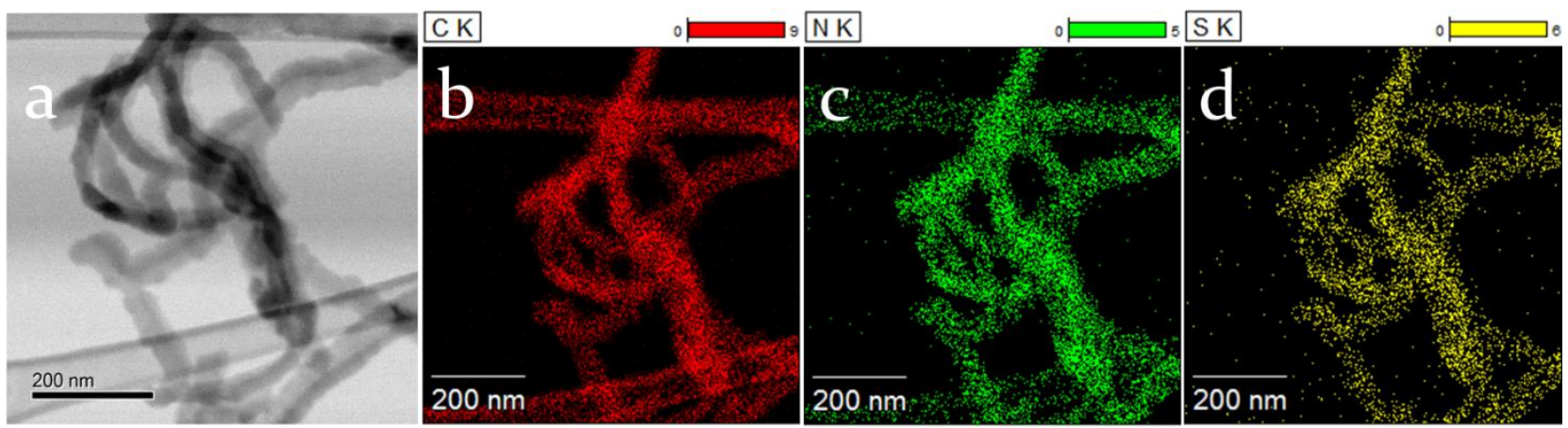

Figure S6. S@PPy composite (precursor): (a) TEM image; (b) elemental mapping of Carbon; (c) elemental mapping of Nitrogen; (d) elemental mapping of Sulfur

To verify that the sulfur was uniformly coated on the surfaces of the split-half tubes of PPy, energy dispersive X-ray spectroscopy (EDS) mapping analysis was carried on the S@PPy composite (precursor) (see Fig. S6). The red spots correspond to the presence of the element carbon (Figure S6(b)), and the green spots correspond to the element nitrogen (Figure S6(c)), in which $\mathrm{C}$ and $\mathrm{N}$ are elements from the polypyrrole. The yellow spots correspond to the element sulfur (Figure S6(d)). The results also show that $\mathrm{S}$ is distributed uniformly throughout the whole area of the $\mathrm{S} @ \mathrm{PPy}$ composite (precursor), which indicates that the sulfur has uniformly coated the surfaces of the split-half tubes of PPy. 